ANDREa PIO de ABREU

\title{
Teste rápido da fludrocortisona na identificação da sensibilidade ao sal
}

\author{
Tese apresentada à Faculdade de \\ Medicina da Universidade de São \\ Paulo para obtenção do título de \\ Doutor em Ciências \\ Programa de Nefrologia \\ Orientador: Prof. Dr. Décio Mion Junior
}

\section{São Paulo}

2015 
Dados Internacionais de Catalogação na Publicação (CIP)

Preparada pela Biblioteca da

Faculdade de Medicina da Universidade de São Paulo

Creprodução autorizada pelo autor

Abreu, Andrea Pio de

Teste rápido da fludrocortisona na identificação da sensibilidade ao sal / Andrea Pio de Abreu. -- São Paulo, 2015.

Tese(doutorado)--Faculdade de Medicina da Universidade de São Paulo. Programa de Nefrologia.

Orientador: Décio Mion Junior.

Descritores: 1.Hipertensão 2.Cloreto de sódio 3.Pressão arterial 4.Fludrocortisona 5.Diagnóstico

USP/FM/DBD-082/15 
Este trabalho foi desenvolvido no Laboratório da Unidade de Hipertensão Arterial do Hospital das Clínicas - Disciplina de Nefrologia da FMUSP. Recebeu apoio financeiro da Fundação de Amparo à Pesquisa do Estado de São Paulo (FAPESP) auxílio regular (2010/17072-6), tendo sido concedida bolsa de doutorado pelo Conselho Nacional de Desenvolvimento Científico e Tecnológico (CNPq). 
"Toda criança começa como um cientista nato. Nós é que tiramos isso delas. Só umas poucas passam pelo sistema com admiração e entusiasmo pela ciência intactos." (Carl Sagan)

É com esta frase na mente que dedico minha tese, em primeiro lugar, aos meus pais. Que me ensinaram a andar antes mesmo de eu ter a ciência do que era a vida. Que valorizaram cada pergunta que fiz, mesmo quando eu mal sabia falar. Que me ensinaram que os maiores passos que podemos dar, são aqueles em direção aos nossos sonhos. Ao meu pai, meu grande amigo, meu maior professor, meu companheiro de profissão, meu exemplo de pessoa e de médico. À minha mãe, meu exemplo de pessoa, de mulher, que com sua "mente brilhante" sempre estimulou meu senso crítico, me fazendo compreender desde cedo que "ninguém manda no meu penso". Meus pais não são minhas referências. Estas vêm no final da nossa história, encerrando todos os capítulos. São meus referenciais... presentes no início de tudo, e ao longo da minha trajetória.

Ao Alexandre, cuja paixão pela ciência sempre me fascinou. Que sempre me incentivou a percorrer a trajetória acadêmica, servindo como grande exemplo de mestre e pesquisador. Tenho muito orgulho em tê-lo como irmão.

Ao meu marido Emanuel, dedico cada letra desta tese. Nestes 16 anos de amor, companheirismo e amizade, foi ele quem mais incentivou e acompanhou minhas escolhas. Que comemorou minha aprovação no vestibular e que me esperou chegar do primeiro dia da faculdade com grande expectativa. Que celebrou minha formatura, e comemorou o final de cada residência. E com expectativa hoje espera a minha defesa. Que sorriu diante de cada conquista, e me deu forças diante das dificuldades. Que soube compreender e tolerar a distância, a ausência, o trabalho intenso. Que acompanhou de perto todas as etapas deste projeto, ouvindo minhas histórias sobre os voluntários, torcendo pelos resultados, procurando entender meus objetivos. Tenho muita sorte em tê-lo como marido e como pai da minha filha. Tenho muita sorte em tê-lo ao meu lado, com suas profundas e raras qualidades.

Aos meus sobrinhos Gabriel e Nicolas, motivos de muitas felicidades em minha vida. À Fé, por ter trazido muitas alegrias para nossa família desde a sua chegada.

E finalmente, dedico à minha doce e amada filhinha Mariana, que ao nascer durante o doutorado me fez sentir uma pessoa muito maior. 
A Deus, por ser meu amigo de todas as horas.

Ao meu orientador Prof. Dr. Decio Mion Jr, pelo apoio irrestrito em todos os momentos do meu doutorado. Por ter confiado em mim e no meu trabalho, me fazendo sempre acreditar que "tudo daria certo". Pelas inúmeras reuniões científicas, pela sua presença constante e interesse em todas as etapas do meu trabalho. Pelo grande médico que demonstrou ser ao se preocupar com a segurança dos voluntários, acima do próprio projeto. Pela sensibilidade que demonstrou ao se importar com minha gestação, independente da tese. Pelos grandes ensinamentos como professor, médico e pesquisador. Pelo grande ensinamento como pessoa. Dr. Decio, um orientador é eterno em nossa trajetória. Obrigada por me permitir ter seu nome gravado na minha história. Receba minha admiração e meu afeto.

Ao Prof. Dr. Isac de Castro, pelo privilégio em tê-lo como estatístico deste trabalho. Pelo privilégio de conviver com pessoa de tamanho valor. Admiro muito sua ética, sua seriedade, seu respeito pelo que faz. Além de grande estatístico, você é também um grande professor. Obrigada pelos grandes ensinamentos.

Ao Giovanio por ter me apoiado quando decidi fazer pós-graduação, me incentivando a percorrer a trajetória acadêmica. No momento em que concluía o seu doutorado, me deu dicas importantes, mostrando que o saldo era positivo. Obrigada pelas sugestões no início do projeto, por me apresentar o Hospital das Clínicas, e por ter me apresentado ao seu orientador, que veio se tornar o nosso.

À Dra Katia Ortega, pelas importantes sugestões no início do meu projeto, contribuindo com sua experiência em sensibilidade ao sal e grande conhecimento em pesquisa clínica. Pelo encaminhamento de voluntários, por ter me apresentado a vários funcionários do laboratório central, por ter acreditado no meu projeto.

Ao Prof. Dr Jose Eluf Neto e a todos os professores da disciplina de Epidemiologia Clínica que se interessaram pelo meu trabalho, contribuindo muito para meu aprendizado sobre testes diagnósticos. 
À Maria Elisa, por ter sido a pessoa que me ajudou no período da coleta de dados. Se prontificando a auxiliar inclusive em funções que não eram suas, pelo grande comprometimento que tem. Obrigada pelo carinho com meus voluntários quando me procuravam fora dos horários. Obrigada pela recepção tão cuidadosa de todos os materiais do laboratório adquiridos para o meu projeto. Obrigada por me auxiliar na procura de artigos científicos quando cheguei na unidade. Obrigada pelo respeito, carinho e pela força. Admiro muito sua competência e seriedade frente ao seu trabalho.

Á minha grande amiga Flávia, minha companheira de pós-graduação! Esta jornada não teria sido a mesma sem você! Obrigada por dividir muitas angústias e alegrias. Obrigada por dividir tantas garrafas de vinho! Obrigada pelo convívio, pela sua amizade tão rara.

Ao corpo editorial do jornal eletrônico semanal do HC ON LINE por divulgar meu projeto, me ajudando a recrutar a maior parte dos voluntários.

Ao Marcio Hahne por divulgar meu projeto no Jornal "O melhor do bairro", me ajudando a recrutar voluntários.

À Karina da Comissão de Ensino e Pesquisa da Divisão do Laboratório Central, por me ajudar a traçar a logística para coleta de exames laboratoriais.

À Ana Maria Lottenberg e toda a equipe da Condieta, pela disponibilidade em formular as dietas alimentares, pelo compromisso assumido quanto ao inquérito alimentar, pelas várias reuniões no início do projeto, por receberem muito bem os meus voluntários ao entregarem as refeições.

À FAPESP, por ter acreditado no meu projeto, tendo concedido a verba para sua realização. A todos os seus funcionários que foram atenciosos ao me tirar dúvidas em relação à liberação de verbas e prestação de contas.

Ao CNPq, por ter me concedido a bolsa, que me ajudou muito!

Preciso também agradecer àqueles que estiveram presentes de forma fundamental em minha vida acadêmica, antes de iniciar a pós-graduação. Ao Prof. Dr. Jose Roberto Coelho da Rocha, por ter sido a primeira pessoa a me 
incentivar na área acadêmica. Por todos os seus ensinamentos à beira do leito, por me mostrar o que significa "pensar com respaldo científico". Meus agradecimentos, meu carinho, e minha eterna saudade. A todos os professores da Universidade Federal Fluminense, em especial ao Prof. Dr. Jose Mauro Calado e Prof. Dr. Walter Machado Pinheiro, que me introduziram no "mundo da pesquisa". A todos os professores dos quatro anos de residência, pelo profundo conhecimento e carinho que me passaram sempre. Em especial ao Prof. Dr. Mauro Asato, que me concedeu inúmeras oportunidades de prática acadêmica.

A todos os meus amigos de turma da UFF, pelo coleguismo e amizade. Aos meus amigos da BP (amigos para sempre!), pelo constante incentivo e pelo grande companheirismo. 


\section{AGRADECIMENTO ESPECIAL}

Aos voluntários que participaram deste estudo, não há palavras que possam expressar minha gratidão, meu respeito e consideração pela forma dedicada com que realizaram todo o protocolo. Jamais os esquecerei. 
Quanto mais o tempo passa, aumenta a chance de nos tornarmos sensiveis ao sal. Quanto mais o tempo passa, aumenta a chance de nos tornarmos resistentes às adversidades da vida. Tiremos então o sal da mesa, e temperemos o nosso modo de viver. 
NORMATIZAÇÃO ADOTADA 
Adaptado do International Committee of Medical Journals Editors (Vancouver).

Universidade de São Paulo, Faculdade de Medicina, Serviço de Biblioteca e Documentação. Guia de apresentação de dissertações, teses e monografias. Elaborado por Anneliese Carneiro da Cunha, Maria Julia de A. L. Freddi, Maria F. Crestana, Marinalva de Souza Aragão, Suely Campos Cardoso, Valéria Vilhena. São Paulo, Serviço de Biblioteca e Documentação: 2011

Abreviaturas dos títulos dos periódicos de acordo com List of Journals Indexed in Index Medicus. 
SUMÁRIO 


\section{Sumário}

\section{LISTA DE ABREVIATURAS \\ LISTA DE TABELAS \\ LISTA DE FIGURAS \\ RESUMO \\ ABSTRACT}

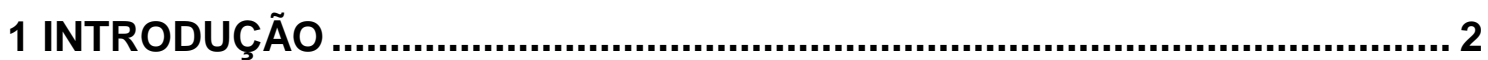

1.1 Fatores determinantes da sensibilidade ao sal .................................... 5

1.2 Importância da Sensibilidade ao sal: Implicações Clínicas e Prognósticas .... 7

1.3 Protocolos para o diagnóstico da sensibilidade ao sal ............................ 10

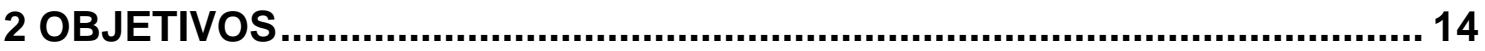

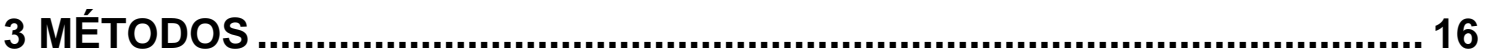

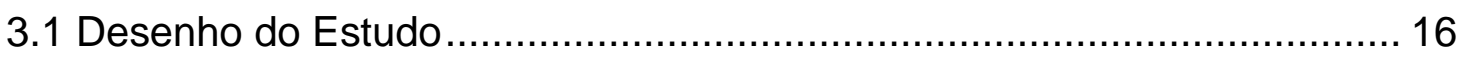

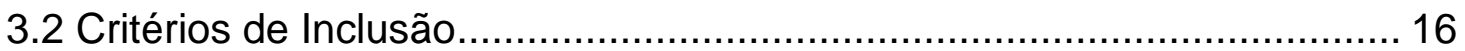

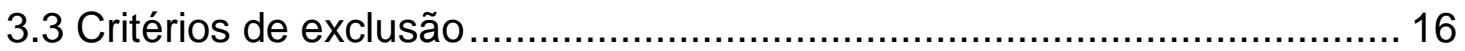

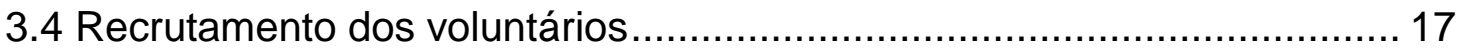

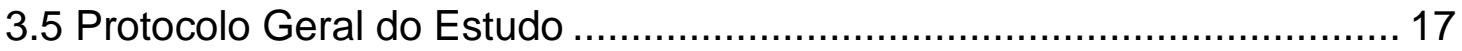

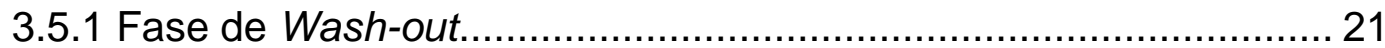

3.5.2 Fase A Ciclo de Dietas Hipossódicas e Hipersódicas....................... 22

3.5.3 Wash-Out 2 ..................................................................... 23

3.5.4 Fase B - Fase do Teste da Fludrocortisona .............................. 23

3.5.5 Exames de análises clínicas ................................................... 23

3.5.6 Medida Residencial da Pressão Arterial ..................................... 24

3.6 Cálculo do tamanho da amostra ……...................................................... 24

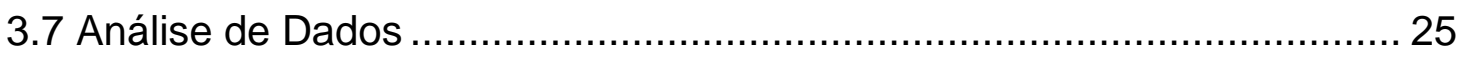

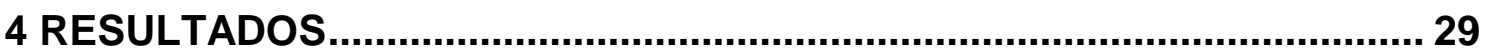

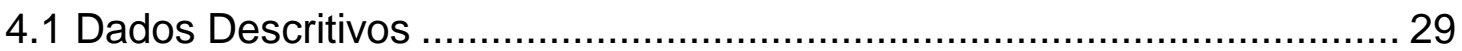

4.2 Dados Analíticos do Teste da Fludrocortisona ....................................... 31

4.2.1 Resultados da Prova de Aleatorização do Ensaio Clínico Cruzado ... 31

4.2.2 Comparação entre os testes (Ciclo de Dietas vs Fludrocortisona) ..... 33

4.2.3 Comparação da variação pressórica (diferença entre medidas de pressão absoluta) entre os grupos............................................. 34

4.2.4 Acurácia do teste da Fludrocortisona........................................... 36

4.3 Dados analíticos da MRPA durante os ciclos de dietas .......................... 38

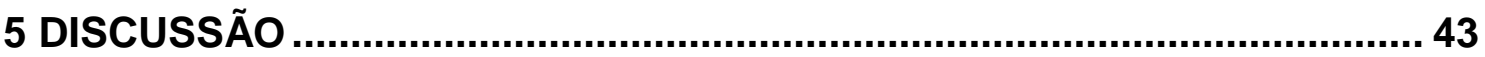

5.1 Discussão do Teste da Fludrocortisona .............................................. 43

5.2 Discussão do estudo da MRPA durante o ciclo de dietas ........................ 47

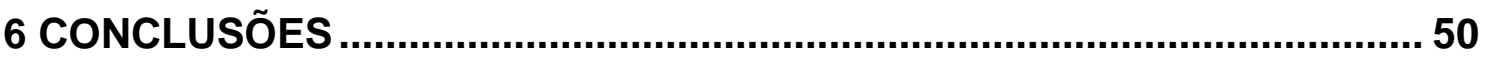

7 ANEXOS

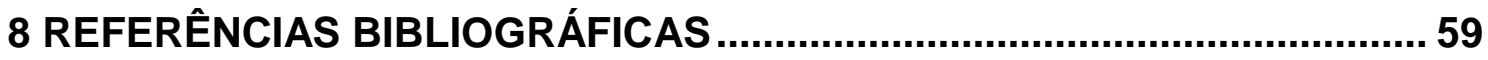


LISTA DE ABREVIATURAS 


\section{LISTA DE ABREVIATURAS}

DM Diabetes Mellitus

DRC Doença renal crônica

ENAC Canais epiteliais de sódio

FMUSP $\quad$ Faculdade de Medicina da Universidade de São Paulo

HAS Hipertensão arterial sistêmica

HETE-20 20-Hydroxyeicosatetraenoic acid

IMC Índice de massa corpórea

MRPA Medida residencial da pressão arterial

OMS Organização Mundial da Saúde

PAS Pressão arterial sistólica

PAM Pressão arterial média

PAD Pressão arterial diastólica

ROC Receiver Operating Characteristic

TGF $\boldsymbol{\beta} \quad$ Transforming growth factor $\beta$ 


\section{LISTA DE TABELAS}

Tabela 1 - Mecanismos envolvidos na sensibilidade ao sal 6

Tabela 2 - Exemplos de protocolos para diagnóstico de sensibilidade ao sal: Métodos e critérios. Adaptado de Sullivan J. Hypertension 1991; 17 [supp I]: I-61-68. NT= Normotensos; HT= Hipertensos; $\mathrm{PAM}=$ Pressão Arterial Média, PAS= Pressão arterial sistólica...... 11

Tabela 3 - Dados demográficos dos voluntários do estudo $(n=30)$ 29

Tabela 4 - Variação da pressão arterial $(\mathrm{mmHg})$ no grupo de sensíveis e resistentes na fase do ciclo de dietas 30

Tabela 5 - Dados Laboratoriais durante a Fase da Fludrocortisona 30

Tabela 6 - Dados laboratoriais durante a Fase com a Fludrocortisona. 31

Tabela 7 - Comparação da pressão arterial $(\mathrm{mmHg})$ dos grupos Ciclo de Dietas e Fludrocortisona entre os dois momentos do estudo.

Tabela 8 - Comparação da pressão arterial $(\mathrm{mmHg})$ entre os grupos Ad-libitum Dieta e Fludrocortisona.

Tabela 9 - Comparação da PAS $(\mathrm{mmHg})$ entre os grupos Dieta vs Fludrocortisona

Tabela 10 - Comparação da PAM $(\mathrm{mmHg})$ entre os grupos Dieta vs Fludrocortisona

Tabela 11 - Comparação da PAD (mmHg) entre os grupos Dieta vs Fludrocortisona

Tabela 12 - Comparação da variação da pressão arterial sistólica entre os grupos Hiper e Hipo (Ciclos de Dietas), entre o D4 e D1 de Fludrocortisona e entre o D7 e D1 de Fludrocortisona

Tabela 13 - Comparação da variação da pressão arterial diastólica entre os grupos Hiper e Hipo (Ciclos de Dietas), entre o D4 e D1 de Fludrocortisona e entre o D7 e D1 de Fludrocortisona

Tabela 14 - Comparação da variação da pressão arterial média entre os grupos Hiper e Hipo (Ciclos de Dietas), entre o D4 e D1 de Fludrocortisona e entre o D7 e D1 de Fludrocortisona

Tabela 15 - Área sob a curva ROC (ASCROC) do 4ำ dia de Fludrocortisona.. 36

Tabela 16 - Área sob a curva ROC (ASCROC) do 7º dia de Fludrocortisona.. 37 
Tabela 17 - Comportamento da PAS, PAM e PAD obtidos pela MRPA durante a dieta ad-libitum e os ciclos de dieta hipo e hipersódica 39

Tabela 18 - Variação da pressão arterial sistólica (PAS) e média (PAM) entre o quarto e sexto dias do ciclo de dietas ............................ 41 
LISTA DE FIGURAS 


\section{LISTA DE FIGURAS}

Figura 1 - Variação da pressão arterial em indivíduos normotensos recebendo incremento progressivo de sódio.

Figura 2 - Mecanismos envolvidos na sensibilidade ao sal

Figura 3 - Curva de Sobrevida de pacientes normotensos e hipertensos, sensíveis ou resistentes ao sal.

Figura 4 - Fatores relacionados à baixa aplicabilidade clínica do teste dos ciclos de dietas para diagnóstico da sensibilidade ao sal.

Figura 5 - Delineamento cross-over do protocolo: Ordem das fases nos dois grupos

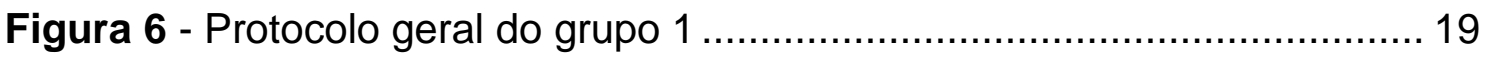

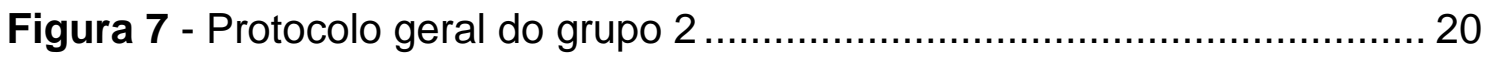

Figura 8 - Curva ROC do Teste da Fludrocortisona (4을 Dia) ........................... 36

Figura 9 - Curva ROC do Teste da Fludrocortisona ( $7^{\circ}$ dia) …........................ 37

Figura 10 - Comportamento da Pressão arterial sistólica (PAS), média (PAM) e diastólica (PAD) obtidos pela MRPA durante a dieta ad-libitum e os ciclos de dieta hipo e hipersódica. $A D L=$ ad-libitum, Hipo = Hipossódica, Hiper $=$ Hipersódica. 


\section{RESUMO}

Abreu AP. Teste rápido da fludrocortisona na identificação da sensibilidade ao sal [tese]. São Paulo: Faculdade de Medicina, Universidade de São Paulo; 2015.

Introdução: A sensibilidade ao sal possui implicações clínicas e prognósticas, porém seu diagnóstico não é habitualmente feito na prática clínica, tendo em vista que o teste de referência é longo e de difícil execução, envolvendo ciclos de dietas hipossódica e hipersódica. O objetivo principal do presente estudo foi avaliar a acurácia do teste da fludrocortisona, quando comparado ao teste de referência. O objetivo secundário foi estudar o teste de referência, avaliando em quanto tempo é possível ser realizado o diagnóstico. Métodos: Foi realizado estudo randomizado e crossover com homens e mulheres hipertensos, sem outras comorbidades, de 40 a 65 anos de idade. Após quatro semanas de washout os pacientes foram randomizados para iniciar pelo teste dos ciclos de dietas ou pelo teste da fludrocortisona. O primeiro consistiu na administração de 7 dias de dieta hipossódica (40 mEq/dia) seguidos por 7 dias de dieta hipersódica (200 $\mathrm{mEq} / \mathrm{dia}$ ), sendo considerados sensíveis os indivíduos com variação da pressão arterial média (PAM) superior a $5 \mathrm{mmHg}$. O segundo consistiu na administração de $0,4 \mathrm{mg} /$ dia do acetato de fludrocortisona por 7 dias, durante ingestão alimentar habitual, sendo avaliada a variação da PAS ou PAM no quarto e sétimo dias do medicamento. O ponto de corte para esta variação foi estudado pela curva ROC, não sendo assumido arbitrariamente. A acurácia do teste foi medida pela área sob a curva ROC. Em relação ao objetivo secundário, foi estudado o comportamento diário da pressão arterial ao longo dos ciclos de dieta, através da MRPA. Resultados: Foram estudados trinta voluntários hipertensos ( $53,7 \pm 7,6$ anos; $72 \pm 10,6 \mathrm{Kg} ; 26 \%$ negros, $10 \%$ pardos e amarelos), sendo $53 \%$ classificados como sensíveis pelo teste de referência. No quarto dia de fludrocortisona, as áreas sob a curva ROC (ASROC) foram de 0,761 $\pm 0,06$ $(\mathrm{p}<0,001)$ para a PAS, de $0,646 \pm 0,072(\mathrm{p}<0,05)$ para a PAM e de $0,554 \pm$ $0,075(p=0,469)$ para a Pressão arterial diastólica (PAD). No sétimo dia de fludrocortisona as ASROC foram 0,849 $\pm 0,05$ ( $p<0,001) ; 0,732 \pm 0,06$ $(\mathrm{p}=0,002)$; e $0,63 \pm 0,07(\mathrm{p}=0,079)$ para respectivamente PAS, PAM e PAD. A maior acurácia foi obtida, portanto, no sétimo dia de fludrocortisona, utilizando a PAS como variável. Neste ponto, com o ponto de corte encontrado de $3 \mathrm{mmHg}$, o teste tem $83 \%$ de sensibilidade e $63 \%$ de especificidade. Em relação ao estudo do teste de referência, observou-se que não há diferença significante da variação pressórica obtida entre o quarto e sexto dias de dieta. Conclusões: A administração do acetato de Fludrocortisona na dose $0,4 \mathrm{mg} /$ dia durante 7 dias - Teste da Fludrocortisona - pode ser utilizado para diagnóstico de sensibilidade ao sal em indivíduos hipertensos de 40 a 65 anos, não obesos e sem outras comorbidades. Em relação ao teste de referência para sensibilidade ao sal, é possível fazer o diagnóstico com duração de 8 dias, não sendo necessário prolongá-lo.

Descritores: hipertensão; cloreto de sódio; pressão arterial; fludrocortisona; diagnóstico. 
ABSTRACT 


\begin{abstract}
Abreu AP. Quick test of fludrocortisone in the identification of salt sensitivity [thesis]. São Paulo: Faculdade de Medicina, Universidade de São Paulo; 2015.
\end{abstract}

Introduction: The salt sensitivity has clinical and prognostic implications; however, its diagnosis is not done in clinical practice, having in mind that the reference test is long and difficult to perform, involving cycles of hyposodic and high salt diets. The main objective of this study was to evaluate the accuracy of fludrocortisone test, when compared to the reference test. The secondary objective was to study the reference test, evaluating the necessary time for diagnosis to be carried out. Methods: It was perfomed a randomized and crossover study was conducted, with hypertensives, with no other comorbidities, 40-65 years old. After four weeks of washout patients were randomized to start, the test cycles diets, or the test of fludrocortisone. The first consisted of the administration of 7 days of low sodium diet (40 mEq / day) followed by seven days of high salt diet (200 mEq / day), being considered sensitive individuals when mean arterial pressure variation (MAP) was greater than $5 \mathrm{mmHg}$. The second consisted in administration of $0.4 \mathrm{mg} /$ day of fludrocortisone acetate for 7 days, during usual dietary intake, being assessed the variation of the systolic (SBP) or MAP in the fourth and seventh days of drug administration. The cutoff point for this variation was studied by the ROC curve, not being taken arbitrarily. The test accuracy was measured by area under the ROC curve. Regarding the secondary objective, the daily blood pressure behavior pattern along the diet cycles was studied, through HBPM. Results: Thirty hypertensives were studied (53.7 \pm 7.6 years; $72 \pm 10.6 \mathrm{~kg} ; 26 \%$ black, $10 \%$ brown and $14 \%$ asian), with $53 \%$ classified as sensitive by the reference test. On the fourth day of fludrocortisone, the areas under the ROC curve (ASROC) were of $0.761 \pm 0.06(p<0.001)$ for SBP, of $0.646 \pm 0.072(p<0.05)$ for the MAP and of $0.554 \pm 0.075(p=0.469)$ for diastolic blood pressure (DBP). On the seventh day of fludrocortisone, the ASROC was $0.849 \pm 0.05(p<0.001) ; 0.732 \pm 0.06(p=$ $0.002)$; and $0.63 \pm 0.07(\mathrm{p}=0.079)$ respectively for SBP, MBP and DBP. Therefore, the highest accuracy occurred on the seventh day of fludrocortisone, using SBP as a variable. At this point, with the cutoff point of $3 \mathrm{mmHg}$ found, the test showed $83 \%$ sensitivity and $63 \%$ specificity. Regarding the study of the reference test, it was observed no significant difference of pressure variation obtained between the fourth and sixth days of diet. Conclusions: The administration of fludrocortisone acetate at a dose $0.4 \mathrm{mg} /$ day over 7 days Fludrocortisone's Test - can be used for identification of salt sensitivity in hypertensives 4065 years old, non-obese and with no other comorbidities. Regarding the reference test for salt sensitivity, it is possible to make the diagnosis with duration of 8 days, not being necessary to extend it.

Descriptors: hypertension; sodium chloride; arterial pressure; fludrocortisone; diagnosis. 


\section{INTRODUÇÃO}

A hipertensão arterial essencial afeta mais de um bilhão de pessoas em todo o mundo. ${ }^{1,2}$, sendo que suas complicações acarretam cerca de 9,4 milhões de mortes a cada ano. Atualmente, é responsável por pelo menos $45 \%$ das mortes por doenças cardíacas e $51 \%$ das mortes por acidente vascular cerebral no mundo. ${ }^{3}$ No Brasil, a hipertensão afeta mais de 30 milhões de pessoas, sendo a maior responsável por cerca de $30 \%$ da mortalidade no país e por 1,2 milhões de internações hospitalares. ${ }^{4}$ Por ser o maior fator de risco para doenças cardiovasculares, cerebrovasculares e renais, sua prevenção e seu controle adequados repercutem de forma impactante na saúde pública.

Dentre os fatores de risco para desenvolvimento da HAS, a ingestão excessiva de sal desempenha papel importante. ${ }^{5}$ Estima-se que no mundo o consumo médio seja de $3.95 \mathrm{~g}$ de sódio ( $10 \mathrm{~g}$ sal) por dia, e que $99,2 \%$ da população adulta exceda os $2 \mathrm{~g}$ de sódio $(5 \mathrm{~g}$ sal) diários recomendados pela OMS. ${ }^{6}$

Grande parte dos estudos demonstraram que há associação entre o sódio e a pressão arterial, e que sua restrição na dieta provoca efeito hipotensor. ${ }^{7,8,9}$ No entanto, não há uniformidade completa entre os autores. Embora grande parte tenha demonstrado esta forte associação, outros estudos revelaram uma fraca relação entre o consumo de sal e o aumento da pressão arterial na população geral. ${ }^{10,11,12,13}$

O estudo INTERSALT ${ }^{10}$, realizado em 52 centros distribuídos por 39 países no mundo e envolvendo cerca de 11 mil pessoas, mostrou inicialmente uma associação positiva entre excreção urinária de sódio nas 24 horas e a pressão arterial sistólica. Porém, ao serem retiradas da análise quatro sociedades primitivas cujo consumo de sal era muito baixo, tal correlação deixou de ser significante. Após uma reanálise dos dados, com correção do viés de diluição de regressão, os pesquisadores encontraram uma relação mais forte entre a excreção urinária de sódio e o aumento da pressão arterial com a idade. ${ }^{14}$ No entanto, outros grupos criticaram os métodos estatísticos utilizados, questionando os resultados obtidos ${ }^{15,16}$ 
Muitos investigadores têm reportado que a hipertensão é rara em sociedades primitivas onde a ingestão de sal é baixa. ${ }^{17,18}$ No entanto, para se estabelecer uma relação de causalidade entre o sal e a hipertensão é necessário que outros possíveis fatores de confusão sejam excluídos, por serem inerentes aos hábitos de vida nestes meios. Estudos de grupos populacionais que migraram de áreas com menor para maior ingestão de sal relatam aumento na pressão arterial. ${ }^{18,19,20}$

No entanto, fatores de confusão, como outros hábitos culturais devem ser considerados como possíveis impactantes na resposta da pressão arterial. Um estudo realizado com índios Kuna no Panamá demonstrou isso. Na região onde mantiveram seus hábitos culturais, porém com ingestão de sal semelhante às sociedades industrializadas (12,3 gramas por dia), os índios não tiveram aumento da pressão arterial com a idade. Por outro lado, os índios que migraram para uma cidade industrializada, onde além da dieta mudaram outros hábitos sociais, apresentaram aumento da pressão arterial. ${ }^{21}$ Estes resultados, portanto, reforçam o conceito de que a menor prevalência de hipertensão nas sociedades primitivas pode não estar relacionada exclusivamente ao menor consumo de sal, mas sim a um conjunto de fatores.

Estudos de intervenção foram realizados com o objetivo de avaliar os efeitos do sal na pressão arterial. ${ }^{22}$ Ensaios clínicos randomizados mostraram que tanto hipertensos jovens quanto idosos apresentaram queda significativa da pressão arterial após restrição de sódio na dieta, porém com magnitude bem superior nos idosos. ${ }^{11}$ Desta forma, ao analisar-se o impacto da redução do sal no comportamento da pressão arterial, observa-se que o mesmo varia conforme o grupo populacional estudado. De fato, em recente metanálise, foi demonstrado que a redução de sal a longo prazo teve impacto significativo na pressão arterial tanto em hipertensos como em normotensos, porém com grande variação na magnitude da queda da pressão arterial. $^{23}$

Muitos estudos prospectivos demonstraram que o maior consumo de sal está associado ao aumento do risco de doença cardiovascular (14\%) e de acidente vascular cerebral (23\%). ${ }^{24}$ No estudo de intervenção Trials of Hypertension Prevention, Phases I and II (TOHP I e II), o grupo submetido à dieta hipossódica teve incidência $25 \%$ menor de eventos cardiovasculares após 
3 anos de seguimento, mesmo tendo apresentado redução modesta da pressão arterial $\left(1,2 \mathrm{mmHg}\right.$ da sistólica e $0,7 \mathrm{mmHg}$ da diastólica). ${ }^{25}$ No entanto, há estudos que mostraram aumento do risco cardiovascular após redução do consumo de sal. ${ }^{26,27,28}$

Grande parte dos resultados conflitantes entre os estudos descritos pode estar relacionada às diferenças inter e intra-populacionais quanto à idade, sexo, raça, prevalência de obesidade, entre outros. Muitos destes estudos consideram que estes grupos são homogêneos no que se refere à resposta da pressão arterial frente ao menor ou maior aporte de sal. Tal heterogeneidade já foi inclusive demonstrada em metanálises, mesmo quando a diferença no delineamento dos estudos foi levada em consideração. ${ }^{11,23}$

É possível que as implicações prognósticas do elevado consumo de sal a longo prazo possam variar dependendo da população envolvida. De fato, mesmo diante do alto consumo de sal na maior parte dos países ocidentais, nem todas as pessoas desenvolvem hipertensão arterial, sugerindo que existem diferentes graus de resposta ao sal, além de outros fatores que podem estar envolvidos como hereditariedade e interação com fatores ambientais. ${ }^{29}$

Em um estudo clássico que analisou a variação da pressão arterial frente à redução do sal na dieta, 82 adultos normotensos apresentaram respostas muito distintas, desde a queda de $15 \mathrm{mmHg}$ até o aumento de $17 \mathrm{mmHg}$ na pressão arterial média. ${ }^{30} \mathrm{O}$ conceito de sensibilidade ao sal é justamente a medida da resposta da pressão arterial em cada indivíduo frente à variação do conteúdo de sal na dieta (Figura 1). ${ }^{31}$ Indivíduos cuja pressão arterial aumenta acima do ponto de corte estabelecido são considerados sensíveis ao sal, enquanto os demais são considerados resistentes.

Observamos que os estudos sobre o impacto da redução do sal na população, assim como outros estudos de intervenção, não levam em consideração a sensibilidade ao sal em hipertensos e normotensos. Sua desconsideração pode ser a causa de muitas discordâncias entre diversos autores. 


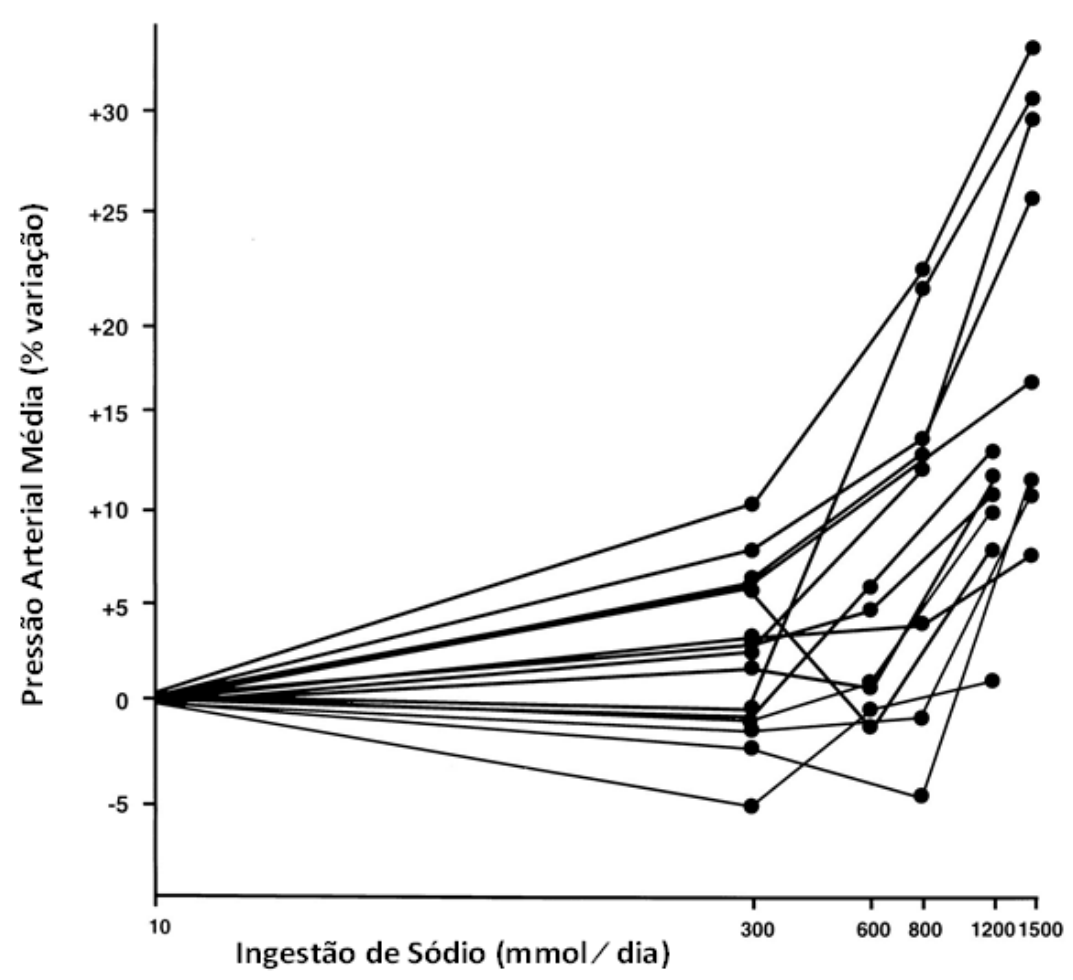

FONTE: Modificado de Weinberger, M.H. 1996; 27: 481-490

Figura 1 - Variação da pressão arterial em indivíduos normotensos recebendo incremento progressivo de sódio.

\subsection{Fatores determinantes da sensibilidade ao sal}

O envolvimento da sensibilidade ao sal na hipertensão arterial tem sido apontado por diversos autores. No entanto, sua patogênese não está ainda bem estabelecida. ${ }^{32}$ Diversos mecanismos envolvidos que interagem de forma complexa já foram descritos, desde alterações genéticas, até mecanismos renais e sistêmicos (Figura 2).

Há muitas evidências sugerindo que pacientes hipertensos sensíveis ao sal manifestam, durante ingestão hipersódica, uma curva de natriurese pressórica anormal, com maior retenção de sódio ${ }^{33}$ e uma adaptação hemodinâmica renal alterada. ${ }^{33-35} \mathrm{Na}$ vigência de um alto consumo de sal, pacientes resistentes possuem uma resposta hemodinâmica semelhante aos normotensos, ou seja, a taxa de filtração glomerular permanece inalterada, o fluxo sanguíneo renal aumenta, e a resistência vascular e fração de filtração diminuem. Já nos pacientes sensíveis, a taxa de filtração glomerular também permanece inalterada, porém com diminuição do fluxo sanguíneo renal e 
aumento da resistência vascular renal, sugerindo um aumento da resistência intraglomerular. Por outro lado, na vigência de dieta hipossódica, pacientes sensíveis e resistentes ao sal apresentam taxa de filtração glomerular, fluxo sanguíneo renal e fração de filtração semelhantes. ${ }^{36}$

Tabela 1 - Mecanismos envolvidos na sensibilidade ao sal

\begin{tabular}{ll}
$\begin{array}{l}\text { Defeitos } \\
\text { Genéticos }\end{array}$ & $\begin{array}{l}\text { Polimorfismos e variantes genéticas } \\
\text { Mutações Genéticas dos canais/transportadores renais } \\
\text { de sódio }\end{array}$ \\
\hline $\begin{array}{l}\text { Mecanismos } \\
\text { Sistêmicos }\end{array}$ & $\begin{array}{l}\text { Tônus simpático aumentado } \\
\text { Supressão insuficiente do sistema renina-angiotensina- } \\
\text { aldosterona } \\
\text { Atividade diminuída do peptídeo natriurético atrial } \\
\text { Redução do hormônio gama estimulador do melanócito } \\
\text { Insulina, síndrome metabólica } \\
\text { Hiperuricemia }\end{array}$
\end{tabular}

\section{Mecanismos}

Renais

\section{Defeitos específicos}

Excesso de atividade do receptor de endotelina $(A)$

Ação alterada da endotelina 1 e da endotelina $(B)$ no ducto coletor

Atividade diminuída da dopamina (desacoplamento)

\section{Defeitos não específicos}

Superprodução de TGF- $\beta$ estimulada pelo sódio

Número reduzido de unidade de néfrons

Atividade diminuída do sistema calicreína-cinina

Síntese alterada do HETE-20 e níveis diminuídos de epoxigenase

Aumento na atividade do sistema nervoso simpático induzido pelos rins

Estresse oxidativo intra-renal

Angiotensina II intra-renal aumentada

Inflamação tubulointersticial 
Quanto à prevalência da sensibilidade ao sal, estudos apontam que cerca de $51 \%$ dos indivíduos hipertensos e $26 \%$ dos normotensos são sensíveis ao sal. ${ }^{37}$ Tal diferença entre normotensos e hipertensos ocorre porque a própria hipertensão arterial é reconhecidamente um fator determinante para a sensibilidade ao sal. Outros fatores reconhecidos são a raça negra ${ }^{38}$, o aumento da idade ${ }^{39}$, obesidade, disfunções renais hereditárias ou adquiridas ${ }^{40}$ e inclusive o tipo de dieta consumida (rica em sal e pobre em potássio). ${ }^{41}$

Estudos têm demonstrado que o baixo peso ao nascer também está associado à sensibilidade ao sal. ${ }^{42}$ No entanto, não está determinado se tal relação deve-se a um defeito intrínseco da função renal, ou à diminuição na massa de néfrons funcionantes. Ambas as possibilidades são suportadas por estudos experimentais com modelos animais, e pela observação de que pacientes com doença renal crônica possuem de fato, maior prevalência de hipertensão sal-sensível.

Outros estudos recentes têm demonstrado ainda que alterações genéticas, dentre elas alterações nos genes relacionados aos canais ENAC localizados no rim, estão implicadas na sensibilidade ao sal. ${ }^{43}$

\subsection{Importância da Sensibilidade ao sal: Implicações Clínicas e Prognósticas}

Há evidências mostrando que indivíduos normotensos e sensíveis ao sal têm maior probabilidade de se tornarem hipertensos. ${ }^{44}$ Neste sentido, a sensibilidade ao sal assume fundamental importância mesmo em indivíduos com pressão arterial normal, configurando-se em um importante fator de risco para o surgimento da hipertensão arterial.

A sensibilidade ao sal relaciona-se ainda ao metabolismo da glicose. Foi demonstrado que indivíduos sensíveis, ao serem submetidos à dieta hipersódica, respondem à ingestão de glicose com excesso da liberação de insulina, ao contrário dos indivíduos resistentes. ${ }^{45}$ Portanto, indivíduos sensíveis possuem maior resistência à insulina quando comparados aos resistentes. ${ }^{46}$

Hipertensos sensíveis ao sal possuem também maior excreção urinária de albumina quando comparados aos resistentes. ${ }^{47}$ Sabe-se que a 
microalbuminúria é um marcador de risco cardiovascular e renal. Neste sentido, tal fato pode estar relacionado às piores implicações prognósticas em indivíduos sensíveis quando comparados aos resistentes.

Outra implicação clínica importante fundamenta-se nos estudos que mostraram, através da medida ambulatorial da pressão arterial, que hipertensos sensíveis ao sal possuem comportamento anormal da pressão arterial a noite. ${ }^{48}$ Nestes indivíduos, o descenso noturno da pressão arterial encontra-se atenuado ou ausente, o que comprovadamente acarreta maior mortalidade a longo prazo. ${ }^{49}$

Diante do exposto, observa-se que o maior risco de desenvolvimento de hipertensão em normotensos, a maior resistência à insulina, a presença de microalbuminúria e ausência do descenso noturno da pressão arterial estão relacionados à sensibilidade ao sal. Todos estes fatores, por sua vez, estão relacionados ao maior risco cardiovascular (Figura 2).

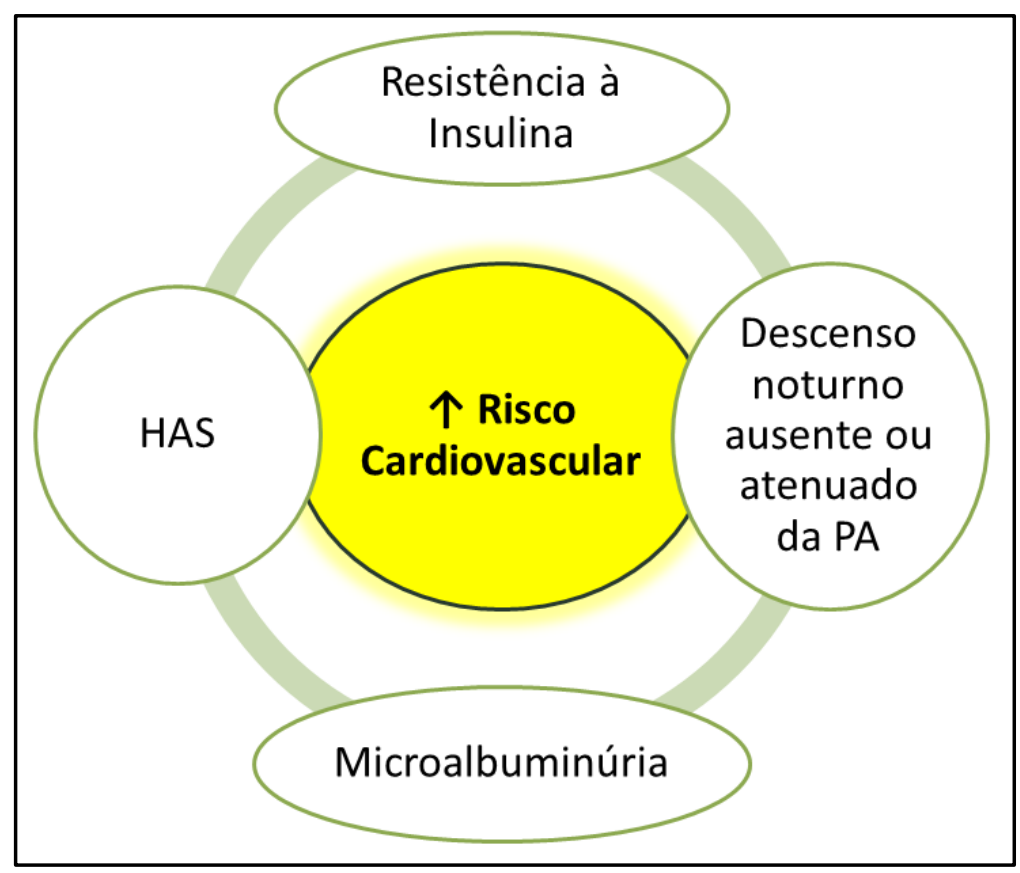

Figura 2 - Mecanismos envolvidos na sensibilidade ao sal.

Reforçando este conceito, os efeitos da sensibilidade a sal na morbidade cardiovascular foram determinados em estudo realizado por Weinberger, onde 430 pacientes normotensos e 278 hipertensos foram avaliados ao longo de 28 anos. Já era esperado que os hipertensos, tanto os sensíveis quanto os resistentes ao sal, tivessem uma sobrevida reduzida quando comparados aos 
normotensos. No entanto, além disto, foi demonstrado que os indivíduos normotensos sensíveis ao sal tiveram uma mortalidade cumulativa similar aos hipertensos, enquanto os normotensos resistentes ao sal tiveram maior sobrevida. Estas observações deram luz a um conceito novo: a relação entre a sensibilidade a sal e mortalidade é independente da elevação da pressão arterial (Figura 3). ${ }^{50}$

Outro estudo avaliou 350 pacientes com hipertensão essencial, mostrando que a taxa de eventos cardiovasculares, tanto fatais como não fatais, foram significativamente mais altos no grupo sensível ao sal. Confirmando o que já havia sido mostrado em estudo experimental prévio ${ }^{51}$, a hipertrofia ventricular esquerda foi também mais frequente no grupo sensível. ${ }^{52}$

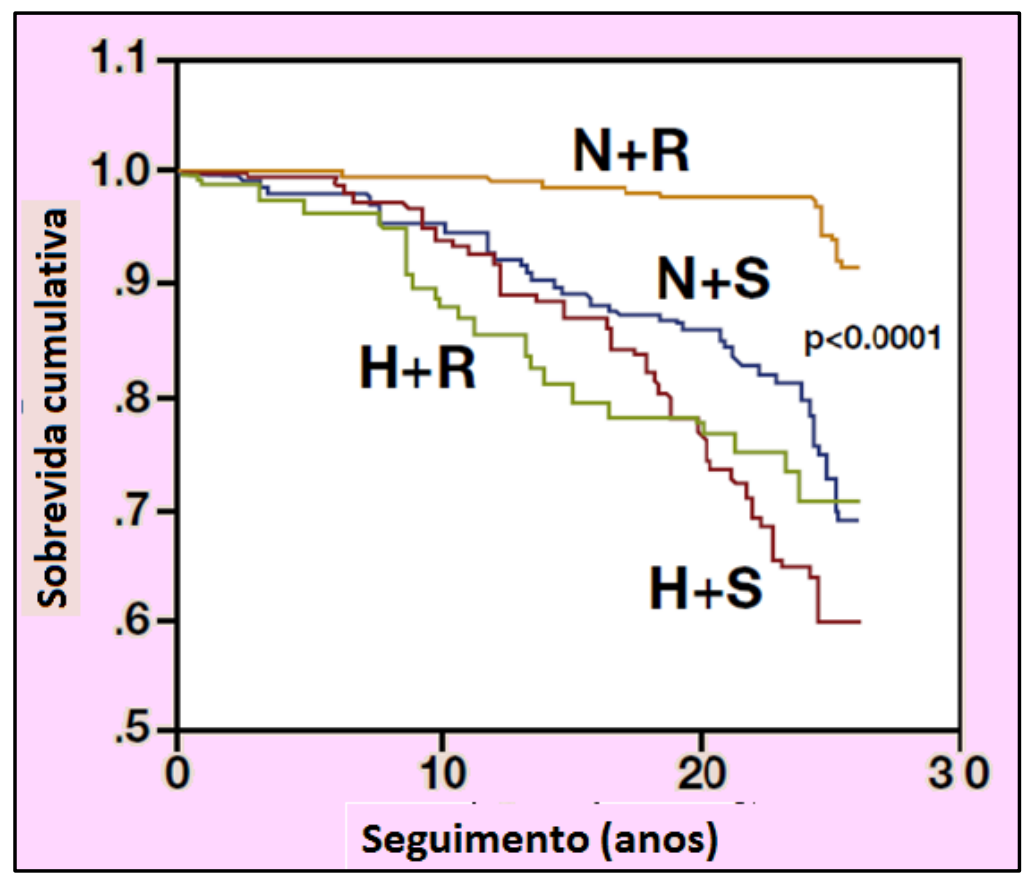

FONTE: Adaptado de Weinberger, HM., Journal Clinical Hypertension, 2002; 4:274-6. N= Normotensos; $\mathrm{H}=$ Hipertensos; $\mathrm{S}=$ Sensíveis; $\mathrm{R}=$ Resistentes

Figura 3 - Curva de Sobrevida de pacientes normotensos e hipertensos, sensíveis ou resistentes ao sal.

Todos estes resultados apontam para a conclusão de que a sensibilidade ao sal é um fator prognóstico independente de risco cardiovascular. ${ }^{52}$ Observase, portanto, que diante dos efeitos da sensibilidade ao sal a longo prazo, identificá-la na prática clínica torna-se importante em normotensos e hipertensos. 


\subsection{Protocolos para o diagnóstico da sensibilidade ao sal}

Desde que Luft et al. (1977) ${ }^{53}$ e Kawasaki et al.(1978) ${ }^{54}$ descreveram respostas variáveis da pressão arterial após períodos curtos de dieta hipo e hipersódica, dezenas de protocolos têm sido descritos para a identificação da sensibilidade ao sal, não havendo uniformidade nos diferentes métodos e critérios empregados (Tabela 2). Geralmente tais critérios envolvem as diferentes variações da pressão arterial após administração, seja por via oral ou venosa, de cloreto de sódio. As diferenças entre os vários métodos ficam por conta da duração das dietas hipo e hipersódicas, da quantidade de sal fornecida, da administração ou não de volume concomitante e diurético, da metodologia utilizada para a medida da pressão arterial, e do valor de corte utilizado para se definir os indivíduos como sensíveis ou resistentes.

Analisando os diversos protocolos existentes, observa-se que o teor de sódio empregado é muito variável entre os estudos, sendo de 9 a $70 \mathrm{mEq} / \mathrm{dia}$ na fase hipossódica, e de 180 a $345 \mathrm{mEq}$ /dia na fase hipersódica. Em relação à ordem dos ciclos, foi demonstrado que não há diferença entre iniciar-se pelo ciclo de dieta hipossódica ou pelo de dieta hipersódica. ${ }^{53}$ Já em relação à duração também é muito variável entre os estudos, sendo que a maior parte utiliza 7 dias em cada ciclo de dietas. Mesmo com tantas diferenças, o teste do ciclo de dietas já mostrou ser reprodutível inclusive em normotensos, sendo na maior parte das vezes adotada a duração de sete dias em cada ciclo. ${ }^{55}$

$A$ adesão às refeições precisa necessariamente ser confirmada nos diversos protocolos, através da excreção urinária de sódio nas 24 horas, sendo recomendada pela Organização Mundial da Saúde como o melhor método para estimar o consumo de sódio. ${ }^{56}$ Tal coleta deve ser realizada pelo participante no final de cada ciclo de dietas, sendo necessária grande adesão para o recolhimento completo da urina no período. Caso haja coleta inadequada no final do segundo ciclo, todo o protocolo deverá ser repetido. 
Tabela 2 - Exemplos de protocolos para diagnóstico de sensibilidade ao sal: Métodos e critérios. Adaptado de Sullivan J. Hypertension 1991; 17 [supp I]: I-61-68. NT= Normotensos; HT= Hipertensos; PAM= Pressão Arterial Média, PAS= Pressão arterial sistólica

\begin{tabular}{|c|c|c|c|}
\hline AUTOR & PROTOCOLO & SUJEITOS & CRITÉRIO \\
\hline Luft, 1977 & $\begin{array}{l}\mathrm{SF} 0,9 \% 2 \mathrm{I}(4 \mathrm{~h}), 10 \mathrm{mEq} \mathrm{Na}, 40 \mathrm{mg} \\
\text { furosemida }\end{array}$ & NT & $\triangle$ PAM $^{*}$ \\
\hline $\begin{array}{l}\text { Kawasaki, } \\
1978\end{array}$ & $\begin{array}{l}109 \mathrm{mEq} \mathrm{Na} \text { ( } 7 \text { dias), } 9 \text { mEq Na ( } 7 \text { dias), } \\
240 \mathrm{mEq} \mathrm{Na} \text { ( } 7 \text { dias) }\end{array}$ & HT & $\begin{array}{l}\triangle \mathrm{PAM} \\
>10 \%\end{array}$ \\
\hline $\begin{array}{l}\text { Sullivan, } \\
1980\end{array}$ & $\begin{array}{l}\text { Ad libitum (1 dia), } 10 \text { mEq Na (4 dias), } \\
\text { Ad libitum (2 dias), } 200 \text { mEq Na (4 dias) }\end{array}$ & NT e HT & $\begin{array}{l}\triangle \mathrm{PAM} \\
>5 \%\end{array}$ \\
\hline Fujita, 1980 & $\begin{array}{l}9 \mathrm{mEq} \mathrm{Na} \text { (7 dias), } 249 \mathrm{mEq} \mathrm{Na} \text { (7 dias), } \\
9 \mathrm{mEq} \mathrm{Na} \text { ( } 4 \text { dias), furosemida } 40 \mathrm{mg} \text { (1 dia) }\end{array}$ & HT & $\begin{array}{l}\triangle \mathrm{PAM} \\
>10 \%\end{array}$ \\
\hline Fujita, 1984 & $\begin{array}{l}\text { Ad libitum, mefruside 25mg/dia ( } 7 \text { dias), } \\
180 \mathrm{mEq} \mathrm{Na} \text { ( } 7 \text { dias) }\end{array}$ & NT e HT & $\triangle$ PAM $^{*}$ \\
\hline $\begin{array}{l}\text { Takeshita, } \\
1982\end{array}$ & 70 mEq Na (7 dias), 345 mEq Na (7 dias) & HT & $\begin{array}{l}\triangle \mathrm{PAM} \\
>10 \%\end{array}$ \\
\hline Ishi, 1983 & $6 \mathrm{~g} \mathrm{NaCl}$ (2 dias), $15 \mathrm{~g} \mathrm{NaCl}$ (5 dias) & NT e HT & $\triangle$ PAM $^{*}$ \\
\hline $\begin{array}{l}\text { Weinberger, } \\
1986\end{array}$ & $\begin{array}{l}\mathrm{SF} 0,9 \% 2 \text { I (4h), } 10 \mathrm{mEq} \mathrm{Na}, 40 \mathrm{mg} \\
\text { furosemida }\end{array}$ & NT e HT & $\begin{array}{l}\triangle \mathrm{PAM} \\
>10 \mathrm{mmHg}\end{array}$ \\
\hline $\begin{array}{l}\text { Sowers, } \\
1988\end{array}$ & $40 \mathrm{mEq} \mathrm{Na}$ (14 dias), $180 \mathrm{mEq} \mathrm{Na} \mathrm{(14} \mathrm{dias)}$ & $\begin{array}{l}\text { NT e HT } \\
\text { negros }\end{array}$ & $\begin{array}{l}\triangle \mathrm{PAM} \\
>5 \% \text { ou } \\
\Delta \mathrm{PAS}>5 \%\end{array}$ \\
\hline $\begin{array}{l}\text { Rocchini, } \\
1989\end{array}$ & $250 \mathrm{mEq} \mathrm{Na}$ (14 dias), $30 \mathrm{mEq} \mathrm{Na} \mathrm{(14} \mathrm{dias)}$ & $\begin{array}{c}\text { NT e } \\
\text { obesos }\end{array}$ & $\triangle$ PAM $^{*}$ \\
\hline $\begin{array}{l}\text { Oshima, } \\
1989\end{array}$ & $3 \mathrm{~g} \mathrm{NaCl}$ (7 dias), $20 \mathrm{~g} \mathrm{NaCl}$ (7 dias) & HT & $\triangle$ PAM $^{*}$ \\
\hline $\begin{array}{l}\text { Sharma, } \\
1989\end{array}$ & $220 \mathrm{mEq} \mathrm{Na}$ (7 dias), 20 mEq Na (7 dias) & NT & $\begin{array}{l}\triangle \mathrm{PAM} \\
>3 \mathrm{mmHg}\end{array}$ \\
\hline $\begin{array}{l}\text { Umeda, } \\
1989\end{array}$ & $34 \mathrm{mEq} \mathrm{Na}$ (8 dias), $340 \mathrm{mEq} \mathrm{Na}$ (8 dias) & HT & $\begin{array}{l}\triangle \mathrm{PAM} \\
>10 \%\end{array}$ \\
\hline
\end{tabular}

* Sem ponto de corte definido. 
Portanto, levando-se em consideração a longa duração do ciclo de dietas, a necessidade da adesão do paciente às refeições hipo e hipersódicas, o custo envolvido na formulação das refeições padronizadas, e a necessidade de duas coletas de sódio na urina de 24 horas, pode-se concluir que tal método diagnóstico de referência para sensibilidade ao sal dificilmente pode ser empregado na prática clínica (Figura 6). Diante da importância já fundamentada deste diagnóstico, termos, portanto, a opção de outro teste que seja mais facilmente exequível e de menor duração, torna-se fundamental.

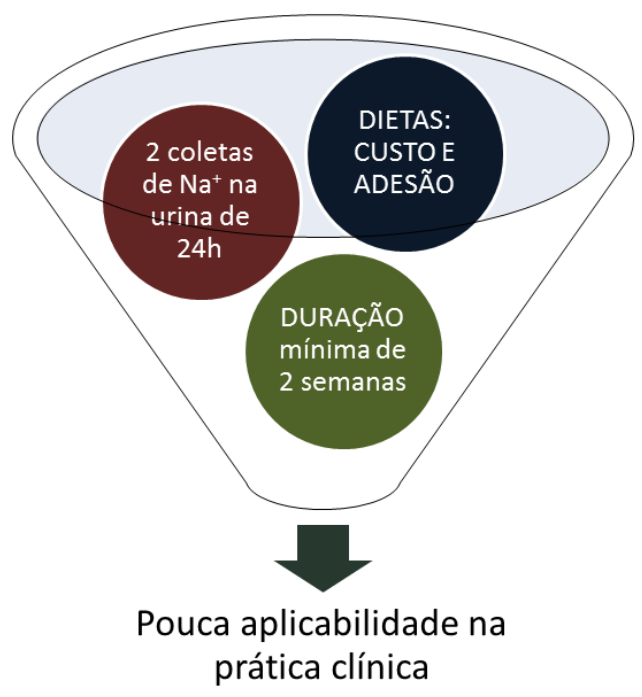

Figura 4 - Fatores relacionados à baixa aplicabilidade clínica do teste dos ciclos de dietas para diagnóstico da sensibilidade ao sal.

O acetato de Fludrocortisona, um medicamento seguro e já utilizado na prática clínica, é um esteróide adrenocortical sintético com ação predominante mineralocorticóide, que atua nos túbulos renais distais acarretando retenção de sódio. Estudo anterior demonstrou que no quarto dia de sua administração, há diminuição significativa da excreção de sódio, na vigência de dieta habitual. ${ }^{57}$ Portanto, ao invés do incremento de sódio entre os ciclos de dietas hipo e hipersódica, pode ser que a retenção de sódio provoque alteração da pressão arterial de forma diferente em sensíveis e resistentes.

Com isto, nossa hipótese é que a administração de Fludrocortisona por via oral, na dose de 0,4mg / dia por 7 dias possa ser usada na identificação dos pacientes sensíveis ao sal, de forma mais rápida e prática que os protocolos tradicionais. 
2- OBJETIVOS 


\section{OBJETIVOS}

O objetivo principal deste estudo foi avaliar a acurácia diagnóstica da administração de Fludrocortisona por via oral, na dose de 0,4mg / dia por 7 dias - Teste da Fludrocortisona - na identificação de pacientes hipertensos sensíveis e resistentes ao sal.

O objetivo secundário foi estudar o comportamento diário da pressão arterial ao longo dos ciclos de dietas, possibilitando verificar com qual duração é possível fazer o diagnóstico da sensibilidade ao sal. 
3- MÉTODOS 


\section{MÉTODOS}

\subsection{Desenho do Estudo}

Estudo experimental do tipo crossover (ou cruzado).

\subsection{Critérios de Inclusão}

- Idade entre 40 e 65 anos;

- Ambos os sexos

- Todas as etnias;

- Índice de Massa Corporal entre 20 e $30 \mathrm{Kg} / \mathrm{m}^{2}$;

- Medida no consultório da pressão arterial sistólica entre 140 e 159 mmHg e diastólica entre 90 e 99 mmHg sem anti-hipertensivos;

- Pressão arterial controlada $(<140 / 90 \mathrm{mmHg})$ na vigência de até duas classes de anti-hipertensivos e que se mantivesse dentro dos limites permitidos (sistólica entre 140 e $159 \mathrm{mmHg}$ e diastólica entre 90 e 99 $\mathrm{mmHg}$ ) após 4 semanas sem anti-hipertensivo;

- Assinar o termo de consentimento livre e esclarecido.

\subsection{Critérios de exclusão}

- Hipertensos estágios 2 e 3 (PA $\geq 160 / 100 \mathrm{mmHg}$ );

- Histórico de causas secundárias de hipertensão;

- Uso de mais de duas classes de anti-hipertensivos no momento da seleção;

- Presença de Diabetes Mellitus ou outras doenças endócrinas;

- Doença renal crônica nos estágios 3 a 5 , definida como taxa de filtração glomerular calculada pela fórmula de Cockcroft-Gault inferior a $60 \mathrm{ml} / \mathrm{min}$ por $1,73 \mathrm{~m}^{2}$;

- Presença de arritmias cardíacas que dificultem a medida da pressão arterial pelo método oscilométrico; 
- Histórico de acidente vascular encefálico, doença coronariana e insuficiência vascular periférica;

- Histórico de insuficiência cardíaca;

- Presença de déficit cognitivo;

- Histórico ou exame clínico sugestivo de insuficiência hepática;

- Distúrbios psiquiátricos ou alcoolismo;

- Uso de fármacos que pudessem interferir na pressão arterial, como anti-inflamatórios não esteroides, contraceptivos orais ou injetáveis, corticosteroides, derivados anfetamínicos.

- Gravidez.

\subsection{Recrutamento dos voluntários}

A inclusão dos pacientes ocorreu em dois períodos: De março a julho de 2011 (70\% dos voluntários) e de janeiro a março de 2012 (30\% dos voluntários). Após cálculo da amostra necessária (28 voluntários), foram recrutados 34 voluntários, sendo 4 excluídos. Portanto, foram estudados 30 voluntários. O recrutamento se fez das seguintes formas:

a) Busca ativa no ambulatório de Hipertensão Arterial da Disciplina de Nefrologia da FMUSP;

b) Recrutamento por meio de mídias impressas e eletrônicas, após aprovação pelo Comitê de Ética da instituição.

\subsection{Protocolo Geral do Estudo}

Após aprovação pelo Comitê de Ética - CAPPesq protocolo № 0343/10 e assinatura o Termo de Consentimento Livre e Esclarecido, os voluntários passíveis de serem incluídos foram submetidos tanto ao período de intervenção com Fludrocortisona como ao período dos ciclos de dietas.

O estudo foi composto pelas seguintes fases: Wash-out, fase $A$ (ciclos de dietas hipo e hipersódicas); wash-out 2 e fase B (teste da fludrocortisona). Os pacientes foram divididos em dois grupos através de randomização em bloco 
de quatro, diferindo apenas na ordem das fases. O primeiro grupo obedeceu a ordem: Wash-out 1, fase A, wash-out 2 e fase $B$. Já o segundo grupo foi submetido à ordem: Wash-out 1 , fase $B$, wash-out 2 e fase $A$ (Figuras 5,6,7).

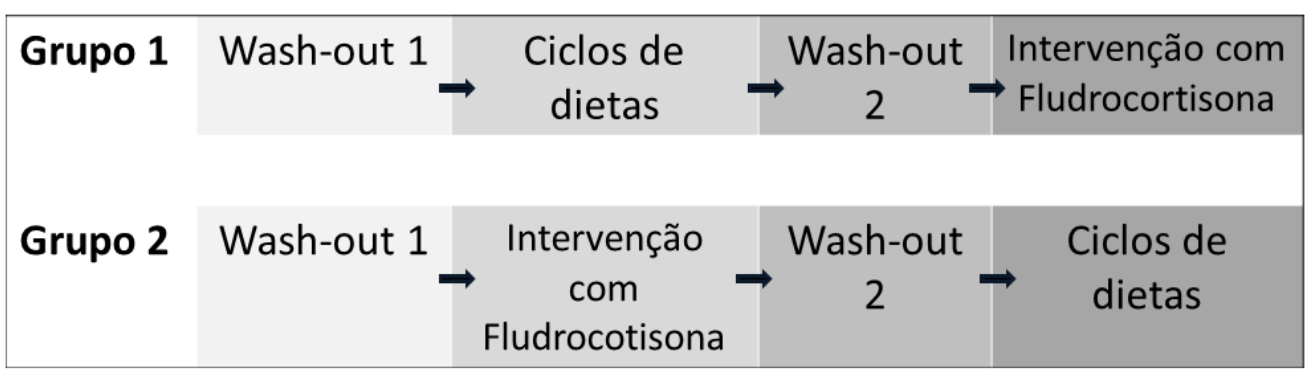

Figura 5 - Delineamento cross-over do protocolo: Ordem das fases nos dois grupos 


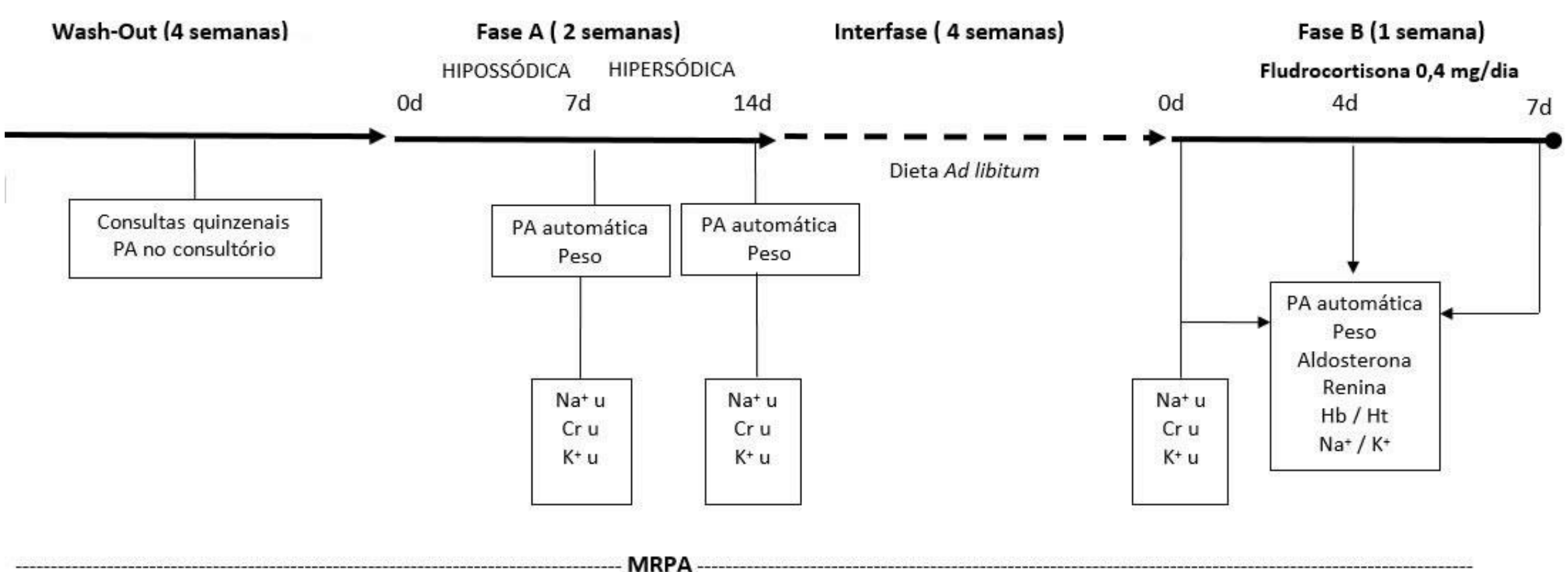

Figura 6 - Protocolo geral do grupo 1

$\mathrm{PA}=$ pressão arterial; $\mathrm{Na}^{+}=$sódio; $\mathrm{K}^{+}=$potássio; $\mathrm{Hb}=$ hemoglobina; $\mathrm{Ht}=$ hematócrito; $\mathrm{Na}^{+} \mathrm{U}$ = sódio urinário; CrU = creatinina urinária, $\mathrm{K}^{+} \mathrm{U}=$ potássio urinário; 


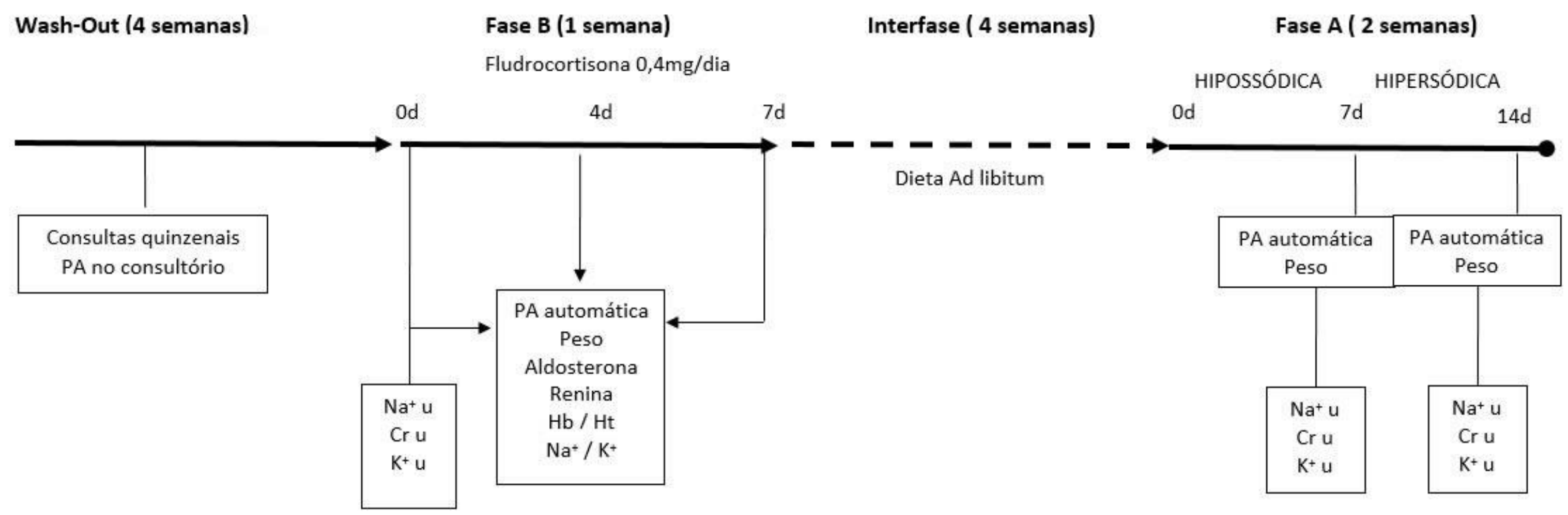

MRPA

Figura 7 - Protocolo geral do grupo 2

$\mathrm{PA}=$ pressão arterial; $\mathrm{Na}^{+}=$sódio; $\mathrm{K}^{+}=$potássio; $\mathrm{Hb}=$ hemoglobina; $\mathrm{Ht}=$ Hematócrito; $\mathrm{Na}^{+} \mathrm{U}=$ sódio urinário; $\mathrm{CrU}=$ creatinina urinária, $\mathrm{K}^{+} \mathrm{U}=$ potássio urinário 


\subsubsection{Fase de Wash-out}

Esta fase teve duração de quatro semanas. No primeiro dia do estudo todos os pacientes tiveram seus medicamentos anti-hipertensivos, eventualmente em uso, suspensos e substituídos por placebo na dose de um comprimido por dia. Neste dia, foi entregue um livreto explicativo englobando todas as atividades a serem realizadas e suas respectivas datas.

A medida da pressão arterial foi realizada na primeira consulta pelo corpo de enfermagem do ambulatório de Nefrologia do Hospital das Clínicas da FMUSP com o aparelho automático tipo oscilométrico Dixtal DX 2710 validado. ${ }^{58}$ Nos pacientes sentados após 5 minutos de repouso, foram realizadas três medidas da pressão arterial com intervalo de cinco minutos entre elas, sendo considerada a média das duas últimas medidas para análise. Os pacientes cuja pressão arterial sistólica e diastólica encontravam-se respectivamente acima de $160 \mathrm{mmHg}$ e $100 \mathrm{mmHg}$, foram excluídos do estudo. Nova consulta foi realizada após duas semanas, seguindo os mesmos procedimentos.

Além da medida da pressão arterial no consultório, os pacientes foram instruídos a realizar a medida residencial da pressão arterial, sendo fornecidos aparelhos automáticos oscilométricos Microlife BP 3AC1-1PC (Microlife Inc, Dunedin, FL, USA), validados conforme protocolo internacional. Os voluntários foram treinados pelo pesquisador executante a respeito da técnica correta, sendo instruídos a medir a pressão arterial em dois momentos do dia (pela manhã e antes do jantar), realizando três medidas consecutivas em cada ocasião, até o final do estudo. ${ }^{59} \mathrm{O}$ manguito foi apropriado para o braço do paciente, sendo medido na consulta inicial. Os resultados da medida da pressão arterial foram posteriormente registrados no software compatível com o aparelho. Os voluntários receberam a orientação de entrar em contato telefônico com o médico pesquisador caso apresentassem níveis pressóricos acima dos valores recomendados, durante todo o protocolo. 


\subsubsection{Fase A Ciclo de Dietas Hipossódicas e Hipersódicas}

Todas as refeições fornecidas aos voluntários foram elaboradas pela firma especializada CONDIETA Centro de Alimentação Dietética Ltda, após inquérito alimentar realizado pela nutricionista. Tais refeições vinham acondicionadas em recipientes apropriados para serem armazenados no congelador, e posteriormente descongelados em forno micro-ondas ou em banho-maria. Os voluntários foram orientados a almoçar e jantar as refeições fornecidas, sem desperdiçar o conteúdo. Foi permitido ainda que consumissem três porções de frutas ao dia, e dois pães de forma no café da manhã, sendo que no ciclo de dietas hipossódicas os pães foram formulados sem sal.

No primeiro ciclo, a dieta formulada foi hipossódica, contendo $40 \mathrm{mEq}$ de sódio por dia, e no segundo ciclo dieta hipersódica, contendo $200 \mathrm{mEq}$ de sódio. Isto permitiu um gradiente entre os ciclos de $160 \mathrm{mEq}$ de sódio por dia.

Para verificação da adesão às refeições, no sétimo dia de cada ciclo os pacientes foram orientados a coletarem toda a urina de 24 horas para a dosagem de sódio, potássio e creatinina urinárias. Os pacientes cujos níveis de sódio urinário foram incompatíveis com a quantidade de sódio administrada na dieta não puderam prosseguir o estudo, sendo então convidados a repetir toda a fase. Os valores considerados adequados de sódio urinário foram estabelecidos em 10 a 50 mEq na dieta hipossódica e entre 150 e 250 mEq na hipersódica.

No sétimo dia de cada ciclo, os pacientes foram pesados e submetidos à medida da pressão arterial pelo método automático, utilizando o aparelho modelo Dixtal DX 2710 validado. ${ }^{58}$ Após 10 minutos em repouso na posição supina, eram realizadas 15 medidas da pressão arterial com intervalos de 2 minutos entre cada medida. Tanto a pesagem quanto a medida da pressão arterial foram realizados pelo médico pesquisador executante no Laboratório de Hipertensão Arterial da Disciplina de Nefrologia da FMUSP. 


\subsubsection{Wash-Out 2}

Os pacientes nesta fase, cuja duração foi de quatro semanas, mantiveram-se em dieta habitual. As consultas médicas foram realizadas quinzenalmente para verificação da pressão arterial no consultório, e os voluntários continuaram realizando a medida residencial da pressão arterial como nas fases anteriores.

\subsubsection{Fase B - Fase do Teste da Fludrocortisona}

Nesta fase, os pacientes permaneceram com sua ingestão alimentar habitual. A excreção de sódio na urina de 24 horas foi realizada antes do início do medicamento.

O acetato de fludrocortisona (9- $\alpha$ fluoridrocortisona, Florinefe ${ }^{\circledR}$, BristolMyers Squib) foi administrado no período da manhã, por via oral, na forma de comprimidos, em dose única de $0,4 \mathrm{mg} /$ dia por 7 dias. A segurança desta dose foi testada em estudo anterior ${ }^{57}$ e é habitualmente utilizada na prática clínica. $^{60,61,62}$

No primeiro, quarto e sétimo dias da administração da Fludrocortisona, os pacientes foram pesados, tendo sua pressão arterial medida pelo método automático, da mesma forma que no final dos ciclos de dieta descritos anteriormente. Também no primeiro, quarto e sétimo dias do medicamento, os pacientes coletaram sangue para exames de análises clínicas.

\subsubsection{Exames de análises clínicas}

A coleta de sangue para exames laboratoriais foi realizada pela manhã, após jejum de 12 horas, no Laboratório do Instituto Central do Hospital das Clínicas da Faculdade de Medicina da Universidade de São Paulo.

O sódio e potássio séricos e urinários foram obtidos através da técnica do eletrodo íon seletivo, e a creatinina urinária foi obtida pelo método colorimétrico cinético, através da reação de Jaffé. Estas análises foram determinadas em 
analisador bioquímico automatizado (modelo COBAS 8000, Plus-Roche Diagnostic System -EUA).

A hemoglobina foi obtida pelo método lauril sulfato de sódio, e o hematócrito foi diretamente detectado a partir do volume de cada eritrócito após impedância. Tais análises foram determinadas em analisador hematológico automatizado (modelo Sysmex XT-2000i, Sysmex - Japão).

A renina foi determinada pelo método de quimioimunoensaio utilizando 0 kit da empresa DiaSorin (Minnesota, EUA), e a aldosterona foi determinada pelo método de radioimunoensaio utilizando o kit comercial Coat a Count Aldosterone da marca Siemens Healthcare Diagnostics Inc. (California, EUA).

\subsubsection{Medida Residencial da Pressão Arterial}

Medida residencial da pressão arterial é o método destinado a realizar registro da pressão arterial fora do ambiente de consultório, pelo próprio paciente ou pessoa capacitada para tal, com equipamento validado e calibrado, durante o período de vigília, obedecendo a um protocolo previamente estabelecido e normatizado. ${ }^{59}$ Desta forma, os pacientes foram instruídos a realizar a MRPA sendo fornecido aparelho automático oscilométrico validado Microlife BP 3AC1-1PC (Microlife Inc, Dunedin, FL, USA).

Os voluntários foram treinados pelo médico, sendo instruídos a medir a pressão arterial em dois momentos do dia (pela manhã e a noite antes do jantar), realizando três medidas consecutivas em cada ocasião durante todos os dias do estudo. O manguito apropriado para o braço do paciente foi selecionado na consulta inicial. Os resultados da medida da pressão arterial foram posteriormente registrados no software compatível com o aparelho.

\subsection{Cálculo do tamanho da amostra}

Considerando-se uma diferença de $5 \mathrm{mmHg}$ da Pressão Arterial Média entre pacientes sensíveis e resistentes ao sal submetidos à dieta hipo e hipersódica, um Desvio Padrão Médio amostral de 4,0, e dados presentes na 
literatura, chegou-se ao tamanho da amostra de 28 pacientes em cada grupo, para um nível de significância de $5 \%$ e um poder do teste de $80 \%$. Como o delineamento foi cruzado, necessitou-se de 28, tendo sido estudados 30 pacientes.

\subsection{Análise de Dados}

Cálculo da Pressão Arterial pelo método automático

Os valores da PAS, PAM e PAD utilizados foram as médias das 15 medidas consecutivas realizadas pelo método automático.

Cálculo da Medida Residencial da Pressão Arterial

Os valores da PAS, PAM e PAD utilizados foram as médias das 6 medidas realizadas em um dia na residência.

Ensaio do Ciclo de dietas

A determinação do valor de corte do teste de sensibilidade ao sal foi definida pela curva ROC. Para tanto, fez-se necessário uma variável categórica e outra contínua que possuíssem associação no mesmo indivíduo.

A variável categórica foi definida na forma binária, sendo considerados os momentos da dieta hipossódica e hipersódica como as categorias.

A variável contínua foi definida pela diferença entre os valores da PAS ou PAM ou PAD, obtida da seguinte forma: Medida da pressão arterial dos pacientes no $7^{\circ}$ dia de dieta hipersódica menos a medida da pressão arterial no $7^{\circ}$ dia de dieta hipossódica. 
A variável categórica no ensaio do teste da fludrocortisona foi definida na forma binária, sendo considerados os momentos sem e com a administração da fludrocortisona como as categorias.

A variável contínua foi definida pela diferença entre os valores da PAS ou PAM ou PAD, obtida da seguinte forma: Medida da pressão arterial dos pacientes no $7^{\circ}$ dia de administração da fludrocortisona menos a medida da pressão no $1^{\circ}$ dia antes da intervenção, e a medida da pressão arterial no $4^{\circ}$ dia de fludrocortisona menos a medida da pressão arterial no $1^{\circ}$ dia antes da intervenção. Durante todos estes momentos, os pacientes encontravam-se em dieta ad libitum.

O valor da nota de corte para a determinação dos pacientes sensíveis a sal no ensaio do teste da fludrocortisona foi encontrado através da curva ROC, correspondendo ao ponto de maior sensibilidade e especificidade.

Prova de Aleatorização do Ensaio Clínico Cruzado

O presente estudo teve delineamento cross-over. Neste tipo de delineamento, todos os tratamentos são aplicados às mesmas unidades experimentais, após agrupá-las em grupos de número igual ao número de tratamentos. Assim, considerando-se que houve dois tratamentos, no caso testes diagnósticos, os indivíduos foram divididos aleatoriamente entre dois grupos, separados pelo wash-out. O período de um mês no wash-out entre os testes foi estabelecido para eliminar efeitos residuais de uma intervenção sobre a subsequente, o que se denomina efeito "carry-over". ${ }^{63}$

Tratando-se de um estudo cruzado, inicialmente devemos avaliar se houve interferência da ordem de tratamento na resposta em cada grupo, ou seja, se o tratamento $A$ - B (ciclo de dietas - fludrocortisona) não foi diferente do B -A (fludrocortisona - ciclo de dietas). Para isto, faz-se necessário preencher o critério de fungibilidade, que é determinado estatisticamente quando não há diferença significante entre os grupos com p>0,10. 


\subsection{Análise estatística}

Os dados contínuos e semi-contínuos foram comparados com a curva de Gauss e determinados em paramétricos e não-paramétricos pelo teste de Distância K-S e Shapiro-Wilks.

Os dados paramétricos foram representados pela média e desvio padrão. Quando comparadas duas amostras independentes foi utilizado o Teste $t$ de Student não pareado, quando comparados dois momentos foi utilizado o Teste t de Student pareado, e quando comparados mais de dois momentos foi utilizado o teste de Analise de Variância para medidas repetidas com pós-teste de Student-Newman-Keuls ou Tukey modificado. Foi considerado para todo estudo $p<0,05$ como significante.

Os dados não paramétricos foram representados por mediana e quartis. Quando comparados dois momentos foi utilizado teste de Wilcoxon, e quando comparados mais de dois momentos foi utilizado o teste de Friedmann com pós-teste de Muller-Dunn.

Dados categóricos foram representados pela frequência absoluta (n) e relativa (\%) e comparados pelo teste de Qui-quadrado de Pearson.

Para determinação da acurácia de um teste diagnostico foi utilizada a curva ROC por meio de suas propriedades:

- Área sob a curva: quando maior que 0,7 apresenta boa capacidade diagnostica;

- Significância Assintótica: capacidade de discriminação do método;

- Nota de Corte: valor de melhor sensibilidade e especificidade. 
4- RESULTADOS 


\section{RESULTADOS}

\subsection{Dados Descritivos}

Foram recrutados 34 voluntários. Três foram excluídos por aumento da pressão arterial acima dos valores permitidos após o período de wash-out, e um foi excluído por não aderir ao ciclo de dietas hipossódicas. Os trinta voluntários que concluíram o estudo tinham idade média de 53,7 \pm 7,6 anos, peso $72 \pm 10,6 \mathrm{Kg}$, e índice de massa corporal de $26 \pm 3 \mathrm{Kg} / \mathrm{m} 2$. Em relação ao gênero, 60\% eram mulheres, e em relação à cor da pele, 50\% eram brancos, $26 \%$ negros, $10 \%$ pardos e $14 \%$ eram amarelos. Antes da suspensão dos medicamentos anti-hipertensivos, a média da PAS medida no consultório foi $146 \pm 12,8 \mathrm{mmHg}$ e a média da PAD foi $91,3 \pm 10,6 \mathrm{mmHg}$ (Tabela 3).

Tabela 3 - Dados demográficos dos voluntários do estudo $(n=30)$

\begin{tabular}{lc}
\hline Idade (anos) & $53,7 \pm 7,6$ \\
\hline Mulheres (\%) & 60 \\
Peso & $72 \pm 10,6$ \\
IMC $\left(\mathrm{Kg} / \mathrm{m}^{2}\right)$ & $26 \pm 3$ \\
Cor da pele $(\%)^{\star}$ & B 50\% / N 26\% / P 10\% / A 14\% \\
\hline PA sistólica consultório $(\mathrm{mmHg})^{\star *}$ & $146 \pm 12,8$ \\
\hline PA diastólica consultório $(\mathrm{mmHg})^{\star *}$ & $91,3 \pm 10,6$ \\
\hline
\end{tabular}

IMC=Índice de Massa Corporal.

${ }^{*} \mathrm{~B}=$ Brancos; $\mathrm{N}=$ Negros; $\mathrm{P}=$ Pardos; $\mathrm{A}=$ Amarelos.

${ }^{* *}$ Com anti-hipertensivos.

No ciclo de dieta hipossódica a média da excreção de sódio foi $40 \pm 25$ $\mathrm{mEq} / \mathrm{vol}$, e no ciclo de dieta hipersódica foi $212,7 \pm 44 \mathrm{mEq} / \mathrm{vol}$. A média das diferenças entre os dois ciclos foi $172,6 \mathrm{mEq} / \mathrm{vol}$.

Pelo critério adotado para sensibilidade ao sal, que consiste na variação da pressão arterial média superior a $5 \mathrm{mmHg}, 16$ pacientes foram classificados 
como sensíveis ao sal e 14 como resistentes. A variação da pressão arterial entre os ciclos nestes indivíduos sensíveis e resistentes está descrito na Tabela 4.

Tabela 4 - Variação da pressão arterial $(\mathrm{mmHg})$ no grupo de sensíveis e resistentes na fase do ciclo de dietas

\begin{tabular}{|c|c|c|}
\hline & $\begin{array}{l}\text { Resistentes } \\
\qquad(n=14)\end{array}$ & $\begin{array}{c}\text { Sensíveis } \\
(n=16)\end{array}$ \\
\hline PAS & $3,0 \pm 8,1$ & $14,1 \pm 5,0$ \\
\hline PAD & $-3,8 \pm 6,1$ & $8,1 \pm 4,7$ \\
\hline PAM & $-1,5 \pm 5,9$ & $10,2 \pm 3,9$ \\
\hline \multicolumn{3}{|c|}{$\begin{array}{l}\text { PAS= Pressão Arterial Sistólica; } P A D=\text { Pressão arterial diastólica; PAM= Pressão Arterial } \\
\text { Média; Dados expressos em média } \pm \text { desvio padrão. } \\
\qquad \mathrm{Na} \text { fase do Teste da Fludrocortisona, houve redução significante da } \\
\text { renina, aldosterona, potássio, hemoglobina e hematócrito tanto no } 4^{\circ} \text { quanto no } \\
\left.7^{0} \text { dia de administração, e o sódio manteve-se estável (Tabelas } 5 \text { e } 6\right) \text {. Nesta } \\
\text { fase, dois voluntários (6\%) referiram sensação de "boca seca", sem outros } \\
\text { sintomas. }\end{array}$} \\
\hline
\end{tabular}

Tabela 5 - Dados Laboratoriais durante a Fase da Fludrocortisona

\begin{tabular}{|c|c|c|c|c|c|c|}
\hline Exame & \multicolumn{2}{|c|}{ D1F } & \multicolumn{2}{|c|}{ D4F } & \multicolumn{2}{|c|}{ D7F } \\
\hline $\mathrm{Na}(\mathrm{mEq} / \mathrm{l})$ & 142,6 & $\pm 2,3$ & 142,4 & $\pm 2,4$ & 143,1 & $\pm 2,2$ \\
\hline $\mathrm{K}(\mathrm{mEq} / \mathrm{l})$ & 4,3 & $\pm 0,4$ & $4,1^{*}$ & $\pm 0,3$ & $3,9^{*} \dagger$ & $\pm 0,3$ \\
\hline $\mathrm{Hb}(\mathrm{g} / \mathrm{dl})$ & 14,2 & $\pm 1,5$ & $13,5^{\star}$ & $\pm 1,6$ & $13,5^{\star}$ & $\pm 1,7$ \\
\hline Ht (\%) & 42,0 & $\pm 3,5$ & $40,4^{*}$ & $\pm 3,9$ & $40,0^{*}$ & $\pm 4,1$ \\
\hline
\end{tabular}


Tabela 6 - Dados laboratoriais durante a Fase com a Fludrocortisona

\begin{tabular}{ccccccccccc}
\hline & \multicolumn{3}{c}{ D1F } & \multicolumn{2}{c}{ D4F } & \multicolumn{3}{c}{ D7F } \\
\hline Exame & Mediana & $\mathbf{2 5 \%}$ & $\mathbf{7 5 \%}$ & Mediana & $\mathbf{2 5 \%}$ & $\mathbf{7 5 \%}$ & Mediana & $\mathbf{2 5 \%}$ & $\mathbf{7 5 \%}$ \\
Aldo (ng/dL) & 8,6 & 7,4 & 12,5 & $4,9^{*}$ & 2,5 & 7,1 & $3,6^{*}$ & 2,6 & 6,7 \\
\hline Renina (uUl/mL) & 6,5 & 3,6 & 15,6 & $3,3^{*}$ & 2,0 & 6,0 & $3,0^{*}$ & 1,6 & 6,0 \\
\hline
\end{tabular}

Aldo $=$ Aldosterona. $\mathrm{D} 1 \mathrm{~F}, \mathrm{D} 4 \mathrm{~F}, \mathrm{D} 7 \mathrm{~F}=1^{\circ}, 4^{\circ}$ e $7^{\circ}$ dias de Fludrocortisona, respectivamente. Dados expressos em mediana e percentis comparados através do Teste de Friedman com pós-teste de Muller-Dunn. ${ }^{*} p<0,05$ vs D1F.

\subsection{Dados Analíticos do Teste da Fludrocortisona}

\subsubsection{Resultados da Prova de Aleatorização do Ensaio Clínico Cruzado}

Observa-se na Tabela 7 que quando comparados os grupos Ciclo de Dietas e Fludrocortisona entre os dois momentos do estudo, não houve diferença estatística entre eles.

A seguir, foi necessário verificar se a ordem dos grupos $(A->B)$ e $(B->A)$ não alterou o padrão de resposta terapêutica em cada um deles, ou seja, se a resposta em cada grupo foi independente da ordem de administração ao paciente.

Observa-se na Tabela 7 que ao compararmos a PAS entre o grupo $A d$ libitum da Dieta $(139,6 \pm 8,1 \mathrm{mmHg})$ com o grupo Ad-libitum da Intervenção com Fludrocortisona (137,3 $\pm 7,8 \mathrm{mmHg})$ não houve diferença significante entre eles. Portanto, foi demonstrado que para todos os parâmetros avaliados houve homogeneidade, definida como $p>0,10$. 
Tabela 7 - Comparação da pressão arterial $(\mathrm{mmHg})$ dos grupos Ciclo de Dietas e Fludrocortisona entre os dois momentos do estudo

\begin{tabular}{|c|c|c|c|c|}
\hline & Grupos & Média & Desvio-padrão & Teste t não pareado \\
\hline \multirow[t]{2}{*}{ PAS ALD } & D1F2 & 138,4 & 6,5 & \multirow{2}{*}{0,596} \\
\hline & F2D1 & 140,9 & 10,1 & \\
\hline \multirow[t]{2}{*}{ PAD ALD } & D1F2 & 88,9 & 8,4 & \multirow{2}{*}{0,926} \\
\hline & F2D1 & 89,4 & 12,0 & \\
\hline \multirow[t]{2}{*}{ PAM ALD } & D1F2 & 105,2 & 6,8 & \multirow{2}{*}{0,798} \\
\hline & F2D1 & 106,5 & 11,2 & \\
\hline \multirow[t]{2}{*}{ PP ALD } & D1F2 & 49,3 & 8,7 & \multirow{2}{*}{0,609} \\
\hline & F2D1 & 51,5 & 5,2 & \\
\hline \multirow[t]{2}{*}{ PAS ADF } & D1F2 & 137,0 & 8,6 & \multirow{2}{*}{0,886} \\
\hline & F2D1 & 137,6 & 7,5 & \\
\hline \multirow[t]{2}{*}{ PAD ADF } & D1F2 & 86,5 & 6,9 & \multirow{2}{*}{0,638} \\
\hline & F2D1 & 88,9 & 10,8 & \\
\hline \multirow[t]{2}{*}{ PAM ADF } & D1F2 & 103,5 & 6,1 & \multirow{2}{*}{0,728} \\
\hline & F2D1 & 105,0 & 8,9 & \\
\hline
\end{tabular}

$\mathrm{PAS}=$ Pressão arterial sistólica; $\mathrm{PAM}=$ Pressão arterial média; $\mathrm{PAD}=$ Pressão arterial diastólica. $\mathrm{ALD}=A d$-libitum pré-ciclo de dietas; $\mathrm{ADF}=A d$-libitum pré-fludrocortisona; $\mathrm{D} 1 \mathrm{~F} 2=$ Grupo Dieta-Fludrocortisona; F2D1 = Grupo Fludrocortisona-Dieta

Tabela 8 - Comparação da pressão arterial $(\mathrm{mmHg})$ entre os grupos Ad-libitum Dieta e Fludrocortisona

\begin{tabular}{|c|c|c|c|c|c|}
\hline Par & Grupo & Média & $\begin{array}{l}\text { Desvio- } \\
\text { padrão }\end{array}$ & $\begin{array}{c}\text { Diferenças } \\
\text { pareadas }\end{array}$ & $\begin{array}{r}\text { Teste t } \\
\text { pareado }\end{array}$ \\
\hline \multirow{2}{*}{ 10 Par } & PAS ALD & 139,6 & 8,1 & \multirow{2}{*}{2,30} & \multirow{2}{*}{0,50} \\
\hline & PAS ADF & 137,3 & 7,8 & & \\
\hline \multirow{2}{*}{ 20 Par } & PAD ALD & 89,1 & 9,8 & \multirow{2}{*}{1,50} & \multirow{2}{*}{0,69} \\
\hline & PAD ADF & 87,6 & 8,6 & & \\
\hline \multirow[t]{2}{*}{ 3 Par } & PAM ALD & 105,8 & 8,7 & \multirow[t]{2}{*}{1,68} & \multirow[t]{2}{*}{0,62} \\
\hline & PAM ADF & 104,1 & 7,2 & & \\
\hline
\end{tabular}

PAS= Pressão arterial sistólica; $P A M=$ Pressão arterial média; $P A D=$ Pressão arterial diastólica. $\mathrm{ALD}=A d$-libitum pré-ciclo de dietas; $\mathrm{ADF}=A d$-libitum pré-fludrocortisona. . Dados apresentados na forma de média \pm desvio padrão, comparados através do Teste T pareado. 
4.2.2 Comparação entre os testes (Ciclo de Dietas vs Fludrocortisona)

Estando demonstrada a homogeneidade em todos os parâmetros avaliados na prova de aleatorização, os testes puderam então ser comparados.

Como demonstrado na Tabela 9, ao comparar-se a pressão arterial sistólica entre os dois grupos, observou-se que o grupo DF (Dieta Fludrocortisona) apresentou PAS maior que o grupo Hipo (138,7 \pm 14,2 $\mathrm{mmHg})$, tanto no $4^{\circ}(148,5 \pm 15,8 \mathrm{mmHg})$ quanto no $7^{\circ}$ dia da Fludrocortisona (152,3 \pm 14,3 mmHg), o mesmo ocorrendo com o grupo Hiper (147,8 \pm 16,0 $\mathrm{mmHg}$ ) em relação ao Hipo. Observou-se ainda que, quando comparado à PAS do $1^{\circ}$ dia de fludrocortisona $(146,2 \pm 12,9 \mathrm{mmHg})$, a PAS do $7^{\circ}$ dia também foi maior $(152,3 \pm 14,3 \mathrm{mmHg})$.

Tabela 9 - Comparação da PAS (mmHg) entre os grupos Dieta vs Fludrocortisona

\begin{tabular}{cccc}
\hline Nome do tratamento & $\mathbf{n}$ & Média & Desvio-padrão \\
\hline PAS HIPO & 30 & 138,7 & 14,2 \\
PAS HIPER & 30 & $147,8^{*}$ & 16,0 \\
PAS D1F (AL) & 30 & $146,2^{*}$ & 12,9 \\
PAS D4F (AL) & 30 & $148,5^{*}$ & 15,8 \\
PAS D7F (AL) & 30 & $152,3^{*} \boldsymbol{\dagger}$ & 14,3 \\
\hline
\end{tabular}

$\mathrm{PAS}=$ Pressão arterial sistólica; D1F, D4F, D7F $=1^{\circ}, 4^{\circ}$ e $7^{\circ}$ dias de Fludrocortisona, respectivamente. $\mathrm{HIPO}=$ Hipossódica; HIPER = Hipersódica.; $\mathrm{AL}=$ Ad-libitum. Dados expressos em média \pm desvio padrão comparados através do Teste de Analise de Variância $(p<0,0001)$ para dados repetidos com pós teste de Tukey. ${ }^{*} p<0,05$ vs Hipo, $\uparrow p<0,05$ vs D1F

Comparando-se a pressão arterial média (PAM) entre os dois grupos, observou-se que o grupo DF (Dieta - Fludrocortisona) apresentou PAM maior que o grupo Hipo $(104,2 \pm 10,8 \mathrm{mmHg})$, tanto no $4^{\circ}(108,6 \pm 10,7 \mathrm{mmHg})$ quanto no $7^{\circ}$ dia $(111,2 \pm 9,5 \mathrm{mmHg})$, o mesmo ocorrendo com o grupo Hiper $(108,9 \pm 10,9 \mathrm{mmHg})$ em relação ao Hipo (Tabela 10).

Comparando-se a pressão arterial diastólica entre os dois grupos, observou-se que o grupo DF (Dieta - Fludrocortisona) não apresentou diferença significante em relação ao grupo Hipo. Desta forma, não foi realizado o pósteste de Tukey (Tabela 11). 
Tabela 10 - Comparação da PAM $(\mathrm{mmHg})$ entre os grupos Dieta vs Fludrocortisona

\begin{tabular}{cccc}
\hline & $\mathbf{n}$ & Média & Desvio-padrão \\
\hline PAM HIPO & 30 & 104,2 & 10,8 \\
PAM HIPER & 30 & $108,9^{*}$ & 10,9 \\
PAM D1F $(\mathbf{A L})$ & 30 & 108,0 & 8,7 \\
PAM D4F $(\mathbf{A L})$ & 30 & $108,6^{*}$ & 10,7 \\
PAM D7F $(\mathbf{A L})$ & 30 & $111,2^{*}$ & 9,5 \\
\hline
\end{tabular}

PAM= Pressão Arterial Média; Hipo= Hipossódica; Hiper=Hipersódica. D1F, D4F, D7F $=1^{\circ} \stackrel{0}{4} \stackrel{0}{ }$ e $7^{\circ}$ dias de Fludrocortisona, respectivamente; $A L=A d$-libitum. Dados expressos em média \pm desvio padrão comparados através do Teste de Analise de Variância para dados repetidos $(p=0,033)$ com pós teste de Tukey. ${ }^{*} p<0,05$ vs Hipo, $\uparrow p<0,05$ vs $D 1 F$

Tabela 11 - Comparação da PAD (mmHg) entre os grupos Dieta vs Fludrocortisona

\begin{tabular}{cccc}
\hline Nome do tratamento & $\mathbf{n}$ & Média & Desvio-padrão \\
\hline PAD HIPO & 30 & 87,0 & 10,3 \\
PAD HIPER & 30 & 89,5 & 9,7 \\
PAD D1F (AL) & 30 & 88,9 & 7,9 \\
PAD D4F (AL) & 30 & 88,7 & 9,6 \\
PAD D7F (AL) & 30 & 90,7 & 9,0 \\
\hline
\end{tabular}

$\mathrm{PAD}=$ Pressão Arterial Diastólica; Hipo= Hipossódica; Hiper=Hipersódica. D1F, D4F, D7F = 1ํㅡㄹ $4^{\circ}$ e $7^{\circ}$ dias de Fludrocortisona, respectivamente; $A L=A d$-libitum. Dados expressos em média \pm desvio padrão comparados através do Teste de Analise de Variância para dados repetidos $(p=0,196)$.

4.2.3 Comparação da variação pressórica (diferença entre medidas de pressão absoluta) entre os grupos.

Ao comparar-se a variação absoluta da PAS entre $01^{\circ}$ e $7^{\circ}$ dias de Fludrocortisona $(6,0 \pm 8,0)$ à variação entre Hiper- Hipo $(9,0 \pm 8,7)$ não houve diferença significante. Porém ao comparar-se a variação entre $1^{\circ}$ e e $4^{\circ}$ dias de Fludrocortisona $(2,3 \pm 9,1)$ com a variação no grupo Hiper-Hipo, tal diferença ocorreu (Tabela 12).

Ao comparar-se a variação absoluta da PAD entre $01^{\circ}$ e $7^{\circ}$ dias de Fludrocortisona $(1,84 \pm 7,8)$ à variação entre Hiper-Hipo $(2,54 \pm 8,0)$ não houve diferença significante. O mesmo ocorreu ao comparar-se a variação entre $1^{\circ}$ e $4^{\circ}$ dias com a variação no grupo Hiper-Hipo, tal como demonstrado na Tabela 13. 
Tabela 12 - Comparação da variação da pressão arterial sistólica entre os grupos Hiper e Hipo (Ciclos de Dietas), entre o D4 e D1 de Fludrocortisona e entre o D7 e D1 de Fludrocortisona

\begin{tabular}{cccc}
\hline PAS & N & Média & Desvio-padrão \\
\hline Hiper-Hipo & 30 & 9,0 & 8,7 \\
D4F-D1F & 30 & $2,3^{*}$ & 9,1 \\
D7F-D1F & 30 & 6,0 & 8,0 \\
\hline
\end{tabular}

PAS= Pressão Arterial Sistólica; Hipo= Hipossódica; Hiper=Hipersódica. D1F, D4F, D7F = 1ํㅡ, $4^{\circ}$ e $7^{\circ}$ dias de Fludrocortisona, respectivamente. Dados expressos em média \pm desvio padrão comparados através do Teste de Analise de Variância para dados não repetidos $(p<0,001)$ com pós teste de Tukey. ${ }^{*} p<0,05$ vs Hiper-Hipo.

Tabela 13 - Comparação da variação da pressão arterial diastólica entre os grupos Hiper e Hipo (Ciclos de Dietas), entre o D4 e D1 de Fludrocortisona e entre o D7 e D1 de Fludrocortisona

\begin{tabular}{cccc}
\hline PAD & N & Média & Desvio-padrão \\
\hline Hiper-Hipo & 30 & 2,54 & 8,0 \\
D4F-D1F & 30 & 0,19 & 7,2 \\
D7F-D1F & 30 & 1,84 & 7,8 \\
\hline
\end{tabular}

$\mathrm{PAD}=$ Pressão Arterial Diastólica; Hipo= Hipossódica; Hiper=Hipersódica. D1F, D4F, D7F = 1으, $4^{\circ}$ e $7^{\circ}$ dias de Fludrocortisona, respectivamente. Dados expressos em média \pm desvio padrão comparados através do Teste de Analise de Variância para dados não repetidos ( $p=0,122)$.

Finalmente, ao comparar-se a variação absoluta da PAM entre $01^{\circ}$ e $7^{\circ}$ dias de Fludrocortisona $(3,25 \pm 7,4)$ com a variação entre Hiper-Hipo $(4,7 \pm 7,7)$ não houve diferença significante. Também não houve diferença ao compararse a variação da PAM entre $1^{\circ}$ e $4^{\circ}$ dias com a variação no grupo Hiper-Hipo, tal como observado na tabela 14.

Tabela 14 - Comparação da variação da pressão arterial média entre os grupos Hiper e Hipo (Ciclos de Dietas), entre o D4 e D1 de Fludrocortisona e entre o D7 e D1 de Fludrocortisona

\begin{tabular}{cccc}
\hline PAM & N & Média & Desvio-padrão \\
\hline Hiper-Hipo & 30 & 4,7 & 7,7 \\
D4F-D1F & 30 & 0,64 & 7,3 \\
D7F-D1F & 30 & 3,25 & 7,4 \\
\hline
\end{tabular}

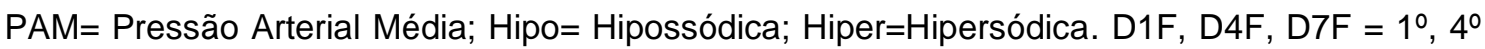
e $7^{\circ}$ dias de Fludrocortisona, respectivamente. Dados expressos em média \pm desvio padrão comparados através do Teste de Analise de Variância para dados não repetidos $(p<0,001)$. 
4.2.4 Acurácia do teste da Fludrocortisona

Ao analisar-se se a acurácia da curva ROC do teste de Fludrocortisona no $4^{\circ}$ dia (Figura 8 e Tabela 15), observou-se que a PAS possui boa capacidade de discriminação ( $A U C=0,761 \pm 0,063 ; p<0,001)$. Já a PAM (AUC=0,646 \pm $0,072 ; p<0,05)$ não possui boa capacidade diagnóstica, o mesmo ocorrendo com a PAD ( $A \cup C=0,554 \pm 0,075 ; p=0,469)$.

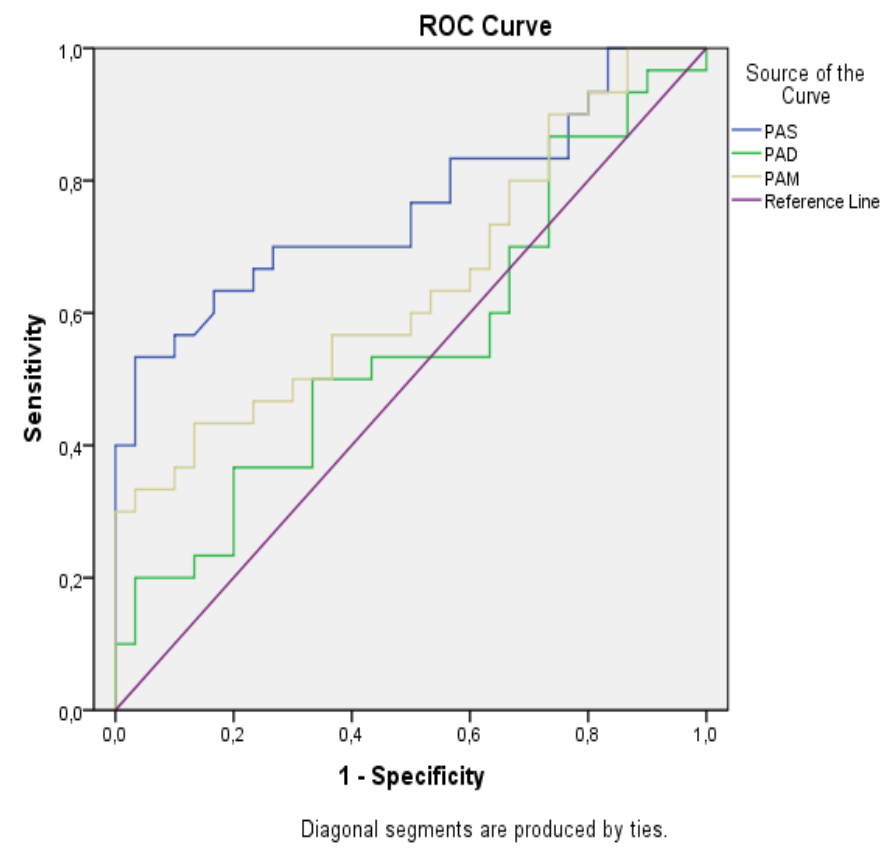

Figura 8 - Curva ROC do Teste da Fludrocortisona (4ํㅡia). Sensitivity= Sensibilidade; Specficity = Especificidade.

Tabela 15 - Área sob a curva ROC (ASCROC) do 4ํ dia de Fludrocortisona

\begin{tabular}{lccccc}
\hline $\begin{array}{l}\text { Variáveis } \\
\text { do Teste }\end{array}$ & ASCROC & Desvio-padrão & $\begin{array}{c}\text { Valor } \\
\text { assintótico }\end{array}$ & \multicolumn{2}{c}{$\begin{array}{c}\text { Assintótico 95\% } \\
\text { IC }\end{array}$} \\
\cline { 5 - 6 } & & & & $\begin{array}{c}\text { Limite } \\
\text { Inferior }\end{array}$ & $\begin{array}{c}\text { Limite } \\
\text { Superior }\end{array}$ \\
\hline PAS & 0,761 & 0,063 & 0,001 & 0,636 & 0,885 \\
\hline PAD & 0,554 & 0,075 & 0,469 & 0,407 & 0,702 \\
\hline PAM & 0,646 & 0,072 & 0,053 & 0,505 & 0,786 \\
\hline
\end{tabular}

$\mathrm{PAS}=$ Pressão arterial sistólica; $\mathrm{PAD}=$ Pressão arterial diastólica; $\mathrm{PAM}=$ Pressão Arterial Média. Dados expressos em valor absoluto \pm desvio padrão. 
Ao analisar-se a acurácia da curva $\mathrm{ROC}$ do teste de Fludrocortisona no $7^{\circ}$ dia (Figura 9 e Tabela 16), observa-se que a PAS (AUC =0,849 $\pm 0,049$; $p<0,001)$ possui boa capacidade diagnóstica, o mesmo ocorrendo com a PAM $(A \cup C=0,732 \pm 0,065 ; p=0,002)$. Já $P A D$ também não possui boa capacidade diagnóstica $(A \cup C=0,632 \pm 0,072 ; p=0,079)$.

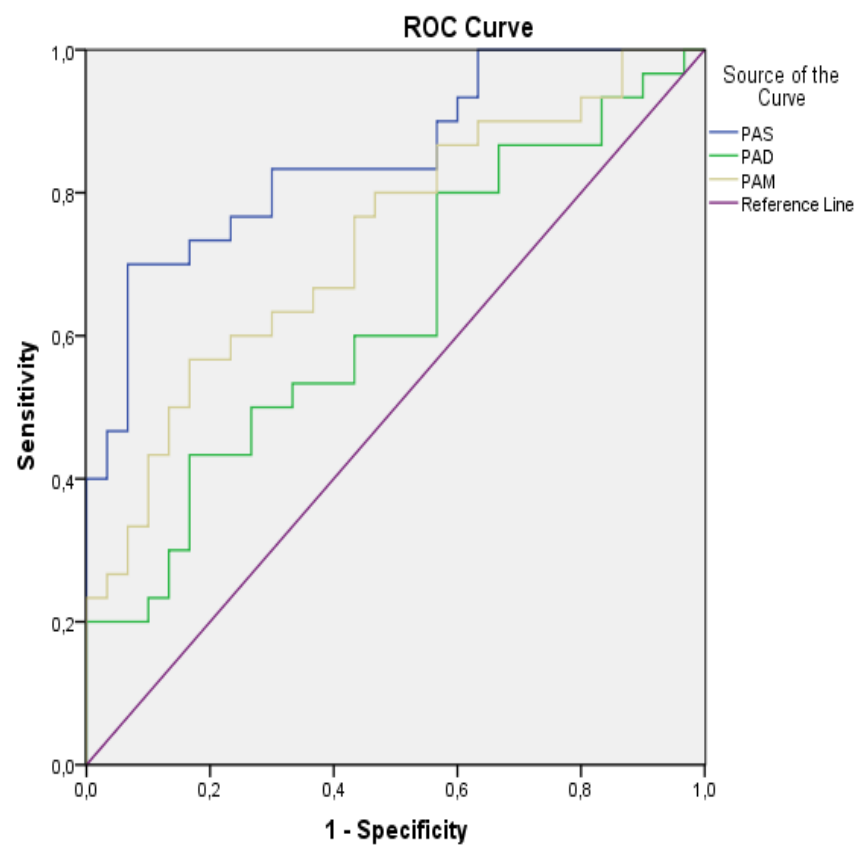

Figura 9 - Curva ROC do Teste da Fludrocortisona ( $7^{\circ}$ dia). Sensitivity = Sensibilidade; Specificity= Especificidade.

Tabela 16 - Área sob a curva ROC (ASCROC) do $7^{\circ}$ dia de Fludrocortisona

\begin{tabular}{lccccc}
\hline $\begin{array}{l}\text { Variáveis } \\
\text { do Teste }\end{array}$ & ASCROC & Desvio-padrão & $\begin{array}{c}\text { Valor } \\
\text { assintótico }\end{array}$ & \multicolumn{2}{c}{\begin{tabular}{c} 
Assintótico 95\% \\
\cline { 4 - 6 }
\end{tabular}} \\
& & & & $\begin{array}{c}\text { Limite } \\
\text { Inferior }\end{array}$ & $\begin{array}{c}\text { Limite } \\
\text { Superior }\end{array}$ \\
PAS & 0,849 & 0,049 & 0,000 & 0,752 & 0,946 \\
PAD & 0,632 & 0,072 & 0,079 & 0,491 & 0,773 \\
PAM & 0,732 & 0,065 & 0,002 & 0,606 & 0,859 \\
\hline
\end{tabular}

$\mathrm{PAS}=$ Pressão arterial sistólica; $\mathrm{PAD}=$ Pressão arterial diastólica; $\mathrm{PAM}=$ Pressão Arterial Média. Dados expressos em valor absoluto \pm desvio padrão. 
A nota de corte para determinação dos pacientes sensíveis ao sal no teste da Fludrocortisona não foi determinado arbitrariamente, sendo estabelecido a partir do valor correspondente ao conjunto de maior sensibilidade e especificidade na curva ROC, sendo de $3 \mathrm{mmHg}$ tanto para PAM como para PAS. Quando realizado por 4 dias e utilizando a variação da PAS $\geq 3 \mathrm{mmHg}$ para diagnosticar quem é sensível ao sal, o teste possui $80 \%$ de sensibilidade e $33 \%$ de especificidade. Utilizando a variação da PAM $\geq 3 \mathrm{mmHg}$, o teste possui sensibilidade de $80 \%$ e especificidade de $53 \%$. Quando realizado por 7 dias e utilizando a variação da PAS $\geq 3 \mathrm{mmHg}$, o teste possui $83 \%$ de sensibilidade e $63 \%$ de especificidade (anexos 1-3).

\subsection{Dados analíticos da MRPA durante os ciclos de dietas}

Inicialmente, foram analisados os comportamentos da PAS, PAM e PAD durante os 6 dias de dieta ad-libitum da semana que antecedeu os ciclos de dietas hipo e hipersódicas, e durante o segundo ao sexto dias destes ciclos (tabela 17 e figura 10).

Durante os 6 dias de dieta ad-libitum, ao analisar-se o comportamento da PAS observou-se que, comparado ao segundo dia, não houve diferença significante do terceiro ao sexto dias. Da mesma forma, não houve diferença no comportamento da PAD. Ao analisar-se a PAM observou-se que houve diferença significante apenas no quinto dia (107 vs 112 mmHg), não sendo portanto, sustentada.

Durante o ciclo de dietas hipossódicas, quando comparado ao segundo dia deste ciclo, houve diminuição significante da PAS no quarto (135 vs $140 \mathrm{mmHg}$ ), quinto (135 vs $140 \mathrm{mmHg}$ ) e sexto dias (132 vs $140 \mathrm{mmHg}$ ). Da mesma forma, houve diminuição significante da PAM no quarto (104 vs $107 \mathrm{mmHg}$ ), quinto (103 vs $107 \mathrm{mmHg}$ ) e sexto dias (101 vs $107 \mathrm{mmHg}$ ). Já em relação à $\mathrm{PAD}$, houve diminuição significante somente no sexto dia (85 vs $91 \mathrm{mmHg}$ ).

Durante o ciclo de dietas hipersódicas, quando comparado ao segundo dia deste ciclo, houve aumento significante da PAS no terceiro (141 vs $136 \mathrm{mmHg}$ ), quarto (140 vs $136 \mathrm{mmHg}$ ), quinto (141 vs $136 \mathrm{mmHg}$ ), e sexto 
dias (141 vs $136 \mathrm{mmHg}$ ). Já em relação à PAM e PAD, não houve aumento significante ao longo deste ciclo.

Tabela 17 - Comportamento da PAS, PAM e PAD obtidos pela MRPA durante a dieta adlibitum e os ciclos de dieta hipo e hipersódica

\begin{tabular}{|c|c|c|c|c|c|c|c|}
\hline & & \multicolumn{2}{|c|}{ PAS } & \multirow{2}{*}{$\frac{\text { PAD }}{\text { Média }}$} & \multicolumn{2}{|c|}{ PAM } & \multirow[b]{2}{*}{ DP } \\
\hline & & Média & DP & & DP & Média & \\
\hline & $2^{\circ}$ Dia & 146 & 16 & 94 & 8 & 112 & 10 \\
\hline A & 3ㅇ Dia & 146 & 14 & 92 & 11 & 110 & 11 \\
\hline D & 4음a & 143 & 14 & 91 & 11 & 108 & 11 \\
\hline \multirow[t]{2}{*}{$\mathbf{L}$} & 5o Dia & 141 & 18 & 90 & 11 & $107^{*}$ & 13 \\
\hline & 60 Dia & 144 & 16 & 91 & 10 & 109 & 11 \\
\hline H & 20 Dia & 140 & 16 & 91 & 11 & 107 & 11 \\
\hline I & 3ํ Dia & 138 & 14 & 90 & 11 & 106 & 11 \\
\hline $\mathbf{P}$ & $4^{\circ}$ Dia & $135^{\star *}$ & 15 & 88 & 9 & $104^{\star \star}$ & 10 \\
\hline \multirow[t]{2}{*}{0} & 5 Dia & $135^{\star *}$ & 15 & 87 & 10 & $103^{\star *}$ & 10 \\
\hline & 60 Dia & $132^{* *}$ & 15 & $85^{\star}$ & 10 & $101^{* \star}$ & 10 \\
\hline $\mathbf{H}$ & 29 Dia & 136 & 14 & 87 & 10 & 103 & 10 \\
\hline I & 3 Dia & $141^{\dagger}$ & 13 & 88 & 10 & 105 & 10 \\
\hline $\mathbf{P}$ & 4 Dia & $140^{\dagger}$ & 11 & 88 & 8 & 105 & 8 \\
\hline E & 5 Dia & $141^{\dagger}$ & 13 & 89 & 8 & 106 & 8 \\
\hline $\mathbf{R}$ & 60 Dia & $141^{\dagger}$ & 13 & 89 & 8 & 106 & 8 \\
\hline
\end{tabular}

$\mathrm{PAS}=$ Pressão arterial sistólica, $\mathrm{PAD}=$ Pressão arterial diastólica, $\mathrm{PAM}=$ Pressão arterial média. Dados expressos em média e desvio padrão da amostra, Analise de Variancia para dados repetidos com pós-teste de Student-Newman e Keus, comparação vs o $2^{\circ}$ dia. * $\mathrm{p}<0,05$ vs $2^{\circ}$ dia de dieta ad-libitum, ${ }^{* *} p<0,05$ vs $2^{\circ}$ dia de dieta hipossódica, ${ }^{\dagger} p<0,05$ vs $2^{\circ}$ dia de dieta hipersódica. 

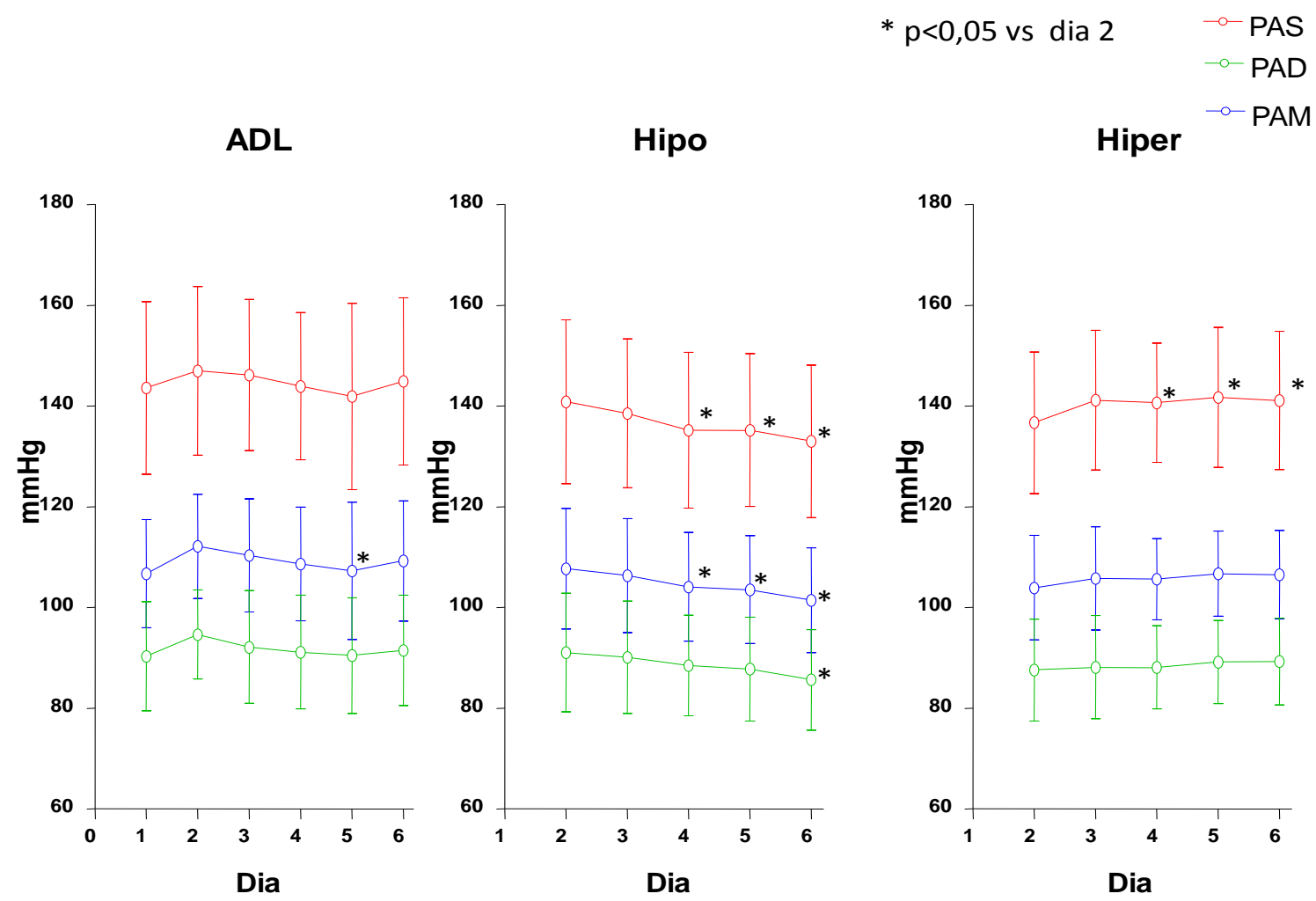

Figura 10 - Comportamento da Pressão arterial sistólica (PAS), média (PAM) e diastólica (PAD) obtidos pela MRPA durante a dieta ad-libitum e os ciclos de dieta hipo e hipersódica. ADL = ad-libitum, Hipo = Hipossódica, Hiper = Hipersódica.

Diante disto, ao observar-se que nos ciclos de dietas hipossódicas houve variação significante da PAS e PAM do quarto ao sexto dias, e no de hipersódicas houve variação significante da PAS também do quarto ao sexto dias quando comparado ao segundo dia, o próximo passo foi analisar a variação da pressão arterial entre estes dias. A PAD não foi estudada, tendo em vista que não é um parâmetro utilizado para definição de sensibilidade ao sal comumente encontrado na literatura. 
Tabela 18 - Variação da pressão arterial sistólica (PAS) e média (PAM) entre o quarto e sexto dias do ciclo de dietas

\begin{tabular}{|c|c|c|c|c|}
\hline & Tempo & Mediana & $25 \%$ & $75 \%$ \\
\hline & $4^{\circ} \mathrm{Dia}$ & 7,25 & $-2,50$ & 12,00 \\
\hline \multirow[t]{3}{*}{ PAS } & $5^{\circ} \mathrm{Dia}$ & 8,00 & $-2,00$ & 14,00 \\
\hline & 6 Dia & 7,50 & 4,63 & 12,75 \\
\hline & $4^{\circ} \mathrm{Dia}$ & 2,75 & $-3,50$ & 6,50 \\
\hline \multirow[t]{2}{*}{ PAM } & $5^{\circ} \mathrm{Dia}$ & 2,25 & $-2,50$ & 8,00 \\
\hline & 6 Dia & 4,50 & 1,50 & 7,38 \\
\hline
\end{tabular}

Dados expressos em mediana e quartis. Teste de Friedman com pós-teste de Müller-Dunn, comparação com o $4^{\circ}$ dia.

Observou-se que não houve diferença significante na variação da PAS e PAM entre o quarto e o quinto dias, e entre o quarto e o sexto dias do ciclo de dietas (tabela 18). 
5- DISCUSSÃO 


\section{DISCUSSÃO}

\subsection{Discussão do Teste da Fludrocortisona}

A importância da sensibilidade ao sal já foi amplamente demonstrada, com implicações clínicas e prognósticas. No entanto, seu diagnóstico permanece distante da prática clínica em função da pouca praticidade do teste dos ciclos de dietas. Este, por sua vez, embora com muitas metodologias distintas, já mostrou ser reprodutível em hipertensos e normotensos, constituindo-se no teste de referência para este diagnóstico. ${ }^{31,37,55}$

Outros testes mais rápidos e práticos foram propostos. Dentre eles, o mais difundido foi o proposto por Weinberger et al. (1983) que conduziram um protocolo rápido em pacientes hipertensos e normotensos. No primeiro dia eram administrados 2 litros de soro fisiológico 0,9\% e no segundo dia, era fornecida dieta com $10 \mathrm{mmol}$ de sódio, associada a $120 \mathrm{mg}$ de furosemida. A pressão arterial era então medida na manhã do $3^{\circ}$ dia, sendo comparada com a pressão arterial do $1^{\circ}$ dia obtida após a salina. O critério de sensibilidade ao sal adotado foi a diminuição na pressão arterial média maior ou igual a $10 \mathrm{mmHg} \cdot{ }^{37}$ Houve uma correlação fraca quando comparado ao ciclo de dietas, porém significativa $(r=0,40, p=0,011)$.

Com o objetivo de comparar o teste rápido proposto por Weiberger com o teste de referência utilizando as dietas, de La Sierra et al. (2002) submeteram 29 pacientes hipertensos essenciais a ambos os testes. ${ }^{64}$ Foram encontrados coeficientes de concordância sistematicamente abaixo de 0,5 , mesmo utilizando diferentes pontos de corte para a variação da pressão arterial. de La Sierra concluiu que o teste de Weinberger pode levar ao erro de classificação sistemática superior a $50 \%$, mesmo utilizando diferentes pontos de corte para variação na pressão arterial.

A necessidade de um novo teste diagnóstico é clara, tanto que há estudos recentes publicados que propuseram novas metodologias, inclusive envolvendo testes genéticos, que não se mostraram aplicáveis até o momento. ${ }^{65,66}$ Neste contexto, encontrar um teste clínico, de baixo custo, prático e com boa acurácia torna-se importante. 
O presente estudo propôs a utilização de um teste para diagnóstico da sensibilidade ao sal sem a necessidade de utilização de dietas hipo e hipersódicas, ou de salina e diurético. Para isto, utilizou o acetato de fludrocortisona na vigência de dieta ad libitum, sem qualquer outro tipo de intervenção. Nossa hipótese inicial era a de que a retenção de sódio causada por este medicamento, pudesse substituir o efeito do gradiente de sal ofertado nas dietas. Para isto, testamos a acurácia do teste no $4^{\circ}$ e no $7^{\circ}$ dias de administração do medicamento.

Pelo teste de referência dos ciclos de dietas, utilizando o ponto de corte de $5 \mathrm{mmHg}$ para a pressão arterial média, nossa amostra teve uma prevalência de $46,7 \%$ de sensíveis e $53,3 \%$ de resistentes ao sal, similar à prevalência descrita na literatura. ${ }^{3,37}$ É provável que tal similaridade tenha ocorrido em função de algumas características demográficas da amostra, sendo elas a presença de quatro cores de pele distintas, a média do IMC na faixa do sobrepeso, a média da idade de 53 anos, e a hipertensão leve destes indivíduos. Caso a amostra tivesse sido composta predominantemente por indivíduos da cor de pele negra, por obesos, ou por idosos, a prevalência de sensíveis provavelmente teria sido maior. Ao contrário, caso tivessem sido incluídos indivíduos normotensos ou muito jovens, a prevalência de resistentes poderia ter sido maior. Tratando-se de um estudo que objetivou avaliar a acurácia de um novo teste diagnóstico, consideramos importante tê-lo estudado em uma amostra cuja prevalência de sensíveis e resistentes obtida pelo teste de referência tenha sido similar àquela encontrada nos hipertensos da população geral.

Quando submetidos ao teste da Fludrocortisona todos os voluntários tiveram diminuição significante nas dosagens de renina e aldosterona plasmáticos, potássio sérico, hemoglobina e hematócrito, mantendo somente o sódio sérico estável. Nota-se, portanto, que o efeito mineralocorticóide do medicamento foi alcançado, como era esperado.

Ao mesmo tempo, não houve efeitos colaterais nesta dosagem. Isto já era esperado, tendo em vista que a dose empregada no teste é habitualmente utilizada na prática clínica. ${ }^{57,60-62}$ 
Como esperado, em relação ao comportamento da pressão arterial no grupo de voluntários, observamos que houve variação significante da pressão arterial sistólica e média tanto no teste de referência, quanto no da Fludrocortisona ( $7^{\circ}$ dia quando comparado ao $1^{\circ}$ dia de administração do medicamento). Só não houve variação significante no $4^{\circ} \stackrel{0}{d i a}$ da Fludrocortisona, provavelmente porque neste dia, a elevação da PA nos pacientes sensíveis não tivesse sido tão significativa ao ponto de impactar na média do grupo. Já a PAD não mostrou elevação significante em ambos os testes, o que corrobora com o fato de não ser um parâmetro habitualmente utilizado no diagnóstico de sensibilidade ao sal, ao contrário da PAS e PAM.

Por se tratarem de diferentes tipos de intervenção, comparamos então a variação pressórica obtida entre os dois testes, e pudemos concluir que a PAS, PAM e PAD foram semelhantes, ou seja, não houve diferença significante entre os testes. Novamente, só houve diferença significante na PAS entre os grupos quando comparamos o quarto dia de Fludrocortisona, pelo mesmo motivo descrito anteriormente, ou seja, provavelmente quatro dias não tivessem sido suficientes para que a variação da PAS nos pacientes sensíveis impactasse na média do grupo.

Diante do exposto, observamos que o gradiente de sódio ofertado nas dietas provocou no grupo o mesmo impacto que a Fludrocortisona, no sentido de aumentar a PAS e a PAM. Estudo anterior que comparou a Fludrocortisona com a administração de salina por via intravenosa também mostrou variações

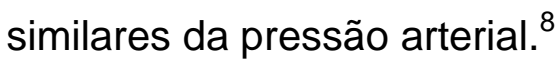

Isto não significava, porém, que o teste da Fludrocortisona possuía capacidade de discriminar indivíduos sensíveis e resistentes corretamente, tal como o teste de referência. Para responder esta questão precisávamos então estudar sua acurácia, objetivo principal deste trabalho.

A acurácia de um teste diagnóstico relaciona-se a sua capacidade de identificar corretamente as pessoas com determinada doença ou condição, excluindo as pessoas que não a possuem. Para isto, tal como feito neste trabalho, faz-se necessário que o novo teste seja comparado com o teste de referência, sendo os mesmos voluntários submetidos a ambos. Quando se trata de testes dicotômicos, a acurácia é geralmente calculada pela proporção 
de indivíduos verdadeiramente positivos com aqueles verdadeiramente negativos em relação aos falso positivos e falso negativos, numa simples tabela de contingência $2 \times 2$. No entanto, muitos testes diagnósticos não produzem resultados diretamente expressos desta forma, por envolverem variáveis categóricas ordinais ou contínuas, como é o caso da pressão arterial. ${ }^{5,7}$

A curva ROC ou receiver operating characteristic que utilizamos neste estudo é uma ferramenta destinada a descrever quantitativamente 0 desempenho de um teste diagnóstico cujo resultado pode ser tratado como uma variável contínua. Formada pelas resultantes pares da sensibilidade e 1 especificidade, possibilita que o teste seja avaliado por diferentes pontos de corte. Além disto, permite analisar a acurácia através da área sob a curva.

Assim, demonstramos que o teste da Fludrocortisona pode ser empregado com boa acurácia após quatro dias de administração do medicamento, utilizando a PAS como variável e o ponto de corte de $3 \mathrm{mmHg}$. Da mesma forma, pode ser empregado após sete dias do medicamento, utilizando tanto a PAS como a PAM, e o mesmo ponto de corte de $3 \mathrm{mmHg}$. Dentro destas possibilidades, constatamos que melhor acurácia é conferida quando definimos como sensível ao sal o paciente com variação da PAS $\geq 3$ $\mathrm{mmHg}$ após 7 dias de Fludrocortisona. Importante ressaltar que este ponto de corte encontrado foi o mesmo utilizado por Sharma e col no protocolo com ciclo de dietas que mostrou reprodutibilidade inclusive em normotensos. ${ }^{55}$

Embora este seja o primeiro trabalho que utilize a Fludrocortisona no diagnóstico de sensibilidade ao sal, este medicamento já é habitualmente utilizado em um dos testes para diagnóstico do Hiperaldosteronismo Primário, conferindo mais uma opção além do teste de supressão com soro fisiológico $0,9 \%$ por via intravenosa, e do teste com ingestão de dieta hipersódica. ${ }^{9}$ Neste caso, já foi demonstrado inclusive em estudo prévio que também utilizou a curva ROC, que o teste da supressão da Fludrocortisona é semelhante ao teste com salina, porém com pontos de corte diferentes. ${ }^{67}$

Consideramos, portanto, que o nosso teste representa uma boa opção no diagnóstico de sensibilidade ao sal. É um teste de baixo custo, mais rápido que o de referência, seguro, e mais facilmente exequível, não sendo necessário o 
emprego de dietas manipuladas e da coleta de sódio na urina de 24 horas para avaliação da adesão.

Nosso trabalho possui algumas limitações que merecem ser destacadas. Foi demonstrado que o teste da Fludrocortisona possui boa acurácia no grupo estudado, ou seja, em indivíduos hipertensos leves, entre 40 e 65 anos e sem outras comorbidades. Para saber se o mesmo se aplica a outros grupos, como normotensos e indivíduos mais jovens ou idosos, outros estudos devem ser realizados. O presente estudo foi desenhado para avaliar a acurácia do teste, sendo necessários outros estudos para avaliar sua reprodutibilidade.

\subsection{Discussão do estudo da MRPA durante o ciclo de dietas}

Demonstramos que o teste de Fludrocortisona é promissor no diagnóstico de sensibilidade ao sal. Até o momento, o teste do ciclo de dietas permanece como sendo o de referência, justamente por ser aplicável em qualquer tipo de pessoa, independente da idade e peso, tendo se mostrado reprodutível.

No entanto, diante de tantos protocolos distintos que se mostram eficazes neste diagnóstico, ainda não foi demonstrado se há diferença em realizar-se o mesmo protocolo por um tempo menor ou maior. Tal demonstração possibilitaria padronizar um tempo determinado, sem a necessidade de se prolongar a administração de dietas, o que implica em maior custo e maior dificuldade na adesão pelo paciente. Desta forma, estudar o comportamento da pressão arterial diariamente ao longo dos dois ciclos de dietas, possibilitaria responder: São necessários 7 dias de cada ciclo, ou podemos realizá-los com duração menor para obtermos o diagnóstico de sensibilidade ao sal? Responder a esta pergunta foi um dos objetivos do presente estudo.

Através da realização da MRPA diariamente, observamos que nos ciclos de dietas hipossódicas houve variação significante da PAS e PAM do quarto ao sexto dias, e no de hipersódicas houve variação significante da PAS também do quarto ao sexto dias quando comparado ao segundo dia. Provavelmente a PAM não aumentou significativamente por depender também da pressão diastólica. Sabemos que, de fato, a PAD não é utilizada nos estudos para diagnóstico de sensibilidade ao sal. 
A partir daí, estudamos o comportamento da pressão do quarto ao sexto dias dos ciclos. Constatamos que tanto a PAS quanto a PAM não alteraram significativamente a partir do $4^{\circ}$ dia, ou seja, o diagnóstico de sensibilidade ao sal pode ser obtido com a duração de quatro dias em cada ciclo, não sendo necessário prolongá-lo até o sexto dia.

A pressão no sétimo dia não foi medida tendo em vista que os voluntários estavam medindo a PA automática no hospital no horário em que mediriam a MRPA em casa, consistindo-se numa limitação do estudo. 


\section{CONCLUSÕES}

A administração do acetato de Fludrocortisona na dose $0,4 \mathrm{mg} / \mathrm{dia}$ durante 7 dias - Teste da Fludrocortisona - permitiu diagnosticar indivíduos sensíveis quando a variação da pressão arterial sistólica ou média foi maior ou igual a $3 \mathrm{mmHg}$ após 7 dias da administração de $0,4 \mathrm{mg}$ de acetado de Fludrocortisona. Este teste pode ser realizado em 4 dias, sendo diagnosticados sensíveis os indivíduos cuja variação da pressão arterial sistólica for maior ou igual a $3 \mathrm{mmHg}$, e resistentes os indivíduos cuja variação for inferior a 3 $\mathrm{mmHg}$. Este teste possui boa acurácia para diagnosticar a sensibilidade ao sal em indivíduos hipertensos entre 40 e 65 anos, e com índice de massa corporal até $30 \mathrm{Kg} / \mathrm{m}^{2}$.

No teste dos ciclos de dietas, cujos protocolos são variáveis quanto à duração de cada ciclo, foi demonstrado que quatro dias em cada ciclo são suficientes para diagnosticar indivíduos sensíveis e resistentes, não sendo necessário prolongar o teste. 
7- ANEXOS 


\section{ANEXOS}

Anexo 1 - Valores (mmHg) da pressão arterial sistólica (PAS), diastólica (PAD) e média (PAM) no $7^{\circ}$ dia do ciclo de dietas hipossódicas (HIPO) e hipersódicas (HIPER) dos 30 voluntários (n).

\begin{tabular}{ccccccc}
\hline $\mathbf{n}$ & $\begin{array}{c}\text { PAS } \\
\text { HIPO }\end{array}$ & $\begin{array}{c}\text { PAD } \\
\text { HIPO }\end{array}$ & $\begin{array}{c}\text { PAM } \\
\text { HIPO }\end{array}$ & $\begin{array}{c}\text { PAS } \\
\text { HIPER }\end{array}$ & $\begin{array}{c}\text { PAD } \\
\text { HIPER }\end{array}$ & $\begin{array}{c}\text { PAM } \\
\text { HIPER }\end{array}$ \\
\hline 1 & 130 & 81 & 95 & 131 & 87 & 102 \\
2 & 130 & 85 & 98 & 140 & 93 & 104 \\
3 & 121 & 81 & 94 & 129 & 85 & 100 \\
4 & 147 & 77 & 101 & 163 & 77 & 95 \\
\hline 5 & 121 & 76 & 87 & 134 & 82 & 96 \\
\hline 6 & 169 & 102 & 116 & 179 & 105 & 120 \\
\hline 7 & 130 & 88 & 99 & 156 & 99 & 115 \\
8 & 163 & 105 & 131 & 177 & 99 & 117 \\
\hline 9 & 156 & 101 & 111 & 142 & 86 & 105 \\
\hline 10 & 125 & 78 & 88 & 129 & 81 & 92 \\
\hline 11 & 154 & 98 & 111 & 150 & 88 & 113 \\
\hline 12 & 151 & 9 & 111 & 152 & 91 & 111 \\
\hline 13 & 130 & 69 & 89 & 141 & 74 & 90 \\
\hline 14 & 121 & 79 & 91 & 130 & 87 & 104 \\
15 & 126 & 87 & 99 & 137 & 91 & 110 \\
\hline 16 & 144 & 99 & 110 & 164 & 99 & 128 \\
\hline 17 & 161 & 98 & 120 & 156 & 92 & 117 \\
\hline 18 & 150 & 91 & 117 & 160 & 98 & 113 \\
\hline 19 & 136 & 72 & 92 & 149 & 83 & 104 \\
\hline 20 & 115 & 78 & 90 & 118 & 78 & 91 \\
\hline 21 & 129 & 89 & 103 & 142 & 95 & 110 \\
\hline 22 & 153 & 88 & 110 & 174 & 97 & 119 \\
\hline 23 & 146 & 83 & 101 & 162 & 95 & 119 \\
\hline 24 & 131 & 78 & 98 & 130 & 74 & 89 \\
\hline 25 & 141 & 99 & 110 & 138 & 88 & 103 \\
\hline 26 & 144 & 94 & 112 & 164 & 112 & 127 \\
\hline 27 & 132 & 86 & 98 & 141 & 85 & 99 \\
\hline 28 & 127 & 83 & 103 & 134 & 72 & 86 \\
\hline 29 & 128 & 67 & 89 & 141 & 83 & 101 \\
\hline 30 & 150 & 98 & 115 & 162 & 102 & 121 \\
\hline & & & & & & \\
\hline
\end{tabular}


Anexo 2 - Valores $(\mathrm{mmHg})$ da pressão arterial sistólica (PAS), diastólica (PAD)

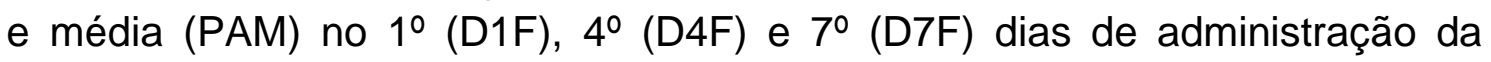
fludrocortisona dos 30 voluntários (n).

\begin{tabular}{cccccccccc}
\hline $\mathbf{n}$ & PAS & PAD & PAM & PAS & PAD & PAM & PAS & PAD & PAM \\
& D1F & D1F & D1F & D4F & D4F & D4F & D7F & D7F & D7F \\
\hline $\mathbf{1}$ & 138 & 94 & 108 & 135 & 92 & 108 & 130 & 83 & 100 \\
\hline $\mathbf{2}$ & 121 & 82 & 93 & 130 & 83 & 95 & 136 & 90 & 103 \\
\hline $\mathbf{3}$ & 135 & 87 & 106 & 128 & 82 & 96 & 134 & 84 & 99 \\
\hline $\mathbf{4}$ & 153 & 89 & 106 & 179 & 96 & 117 & 153 & 78 & 97 \\
\hline $\mathbf{5}$ & 146 & 87 & 105 & 143 & 82 & 98 & 135 & 78 & 95 \\
\hline $\mathbf{6}$ & 168 & 99 & 115 & 168 & 101 & 119 & 172 & 103 & 119 \\
\hline $\mathbf{7}$ & 143 & 92 & 106 & 141 & 89 & 106 & 155 & 97 & 113 \\
\hline $\mathbf{8}$ & 168 & 94 & 119 & 182 & 107 & 126 & 175 & 101 & 130 \\
\hline $\mathbf{9}$ & 148 & 86 & 104 & 142 & 78 & 94 & 158 & 98 & 114 \\
\hline $\mathbf{1 0}$ & 133 & 81 & 92 & 134 & 69 & 91 & 134 & 77 & 97 \\
\hline $\mathbf{1 1}$ & 146 & 94 & 114 & 149 & 91 & 112 & 162 & 93 & 113 \\
\hline $\mathbf{1 2}$ & 156 & 93 & 114 & 154 & 90 & 110 & 156 & 89 & 112 \\
\hline $\mathbf{1 3}$ & 145 & 72 & 93 & 141 & 67 & 81 & 160 & 78 & 94 \\
\hline $\mathbf{1 4}$ & 143 & 99 & 114 & 137 & 90 & 109 & 149 & 98 & 113 \\
\hline $\mathbf{1 5}$ & 134 & 82 & 101 & 131 & 81 & 100 & 131 & 83 & 102 \\
\hline $\mathbf{1 6}$ & 150 & 99 & 116 & 144 & 89 & 108 & 146 & 93 & 111 \\
\hline $\mathbf{1 7}$ & 161 & 97 & 117 & 155 & 95 & 111 & 170 & 92 & 116 \\
\hline $\mathbf{1 8}$ & 150 & 89 & 111 & 168 & 95 & 112 & 162 & 93 & 112 \\
\hline $\mathbf{1 9}$ & 148 & 83 & 93 & 158 & 78 & 102 & 164 & 83 & 101 \\
\hline $\mathbf{2 0}$ & 127 & 82 & 97 & 142 & 96 & 107 & 141 & 95 & 110 \\
\hline $\mathbf{2 1}$ & 146 & 95 & 106 & 137 & 93 & 105 & 151 & 101 & 113 \\
\hline $\mathbf{2 2}$ & 180 & 101 & 120 & 187 & 109 & 120 & 188 & 102 & 119 \\
\hline $\mathbf{2 3}$ & 149 & 88 & 107 & 146 & 82 & 105 & 155 & 80 & 103 \\
\hline $\mathbf{2 4}$ & 140 & 79 & 95 & 145 & 85 & 99 & 139 & 76 & 89 \\
\hline $\mathbf{2 5}$ & 131 & 86 & 100 & 131 & 77 & 95 & 151 & 100 & 116 \\
\hline $\mathbf{2 6}$ & 157 & 100 & 120 & 154 & 97 & 118 & 164 & 105 & 125 \\
\hline $\mathbf{2 7}$ & 151 & 94 & 113 & 144 & 92 & 105 & 149 & 94 & 107 \\
\hline $\mathbf{2 8}$ & 143 & 78 & 101 & 163 & 90 & 112 & 161 & 100 & 109 \\
\hline $\mathbf{2 9}$ & 130 & 71 & 91 & 136 & 85 & 106 & 143 & 83 & 102 \\
\hline $\mathbf{3 0}$ & 140 & 90 & 106 & 146 & 92 & 110 & 141 & 87 & 105 \\
\hline & & & & & & & & & \\
\hline
\end{tabular}


Anexo 3 - Valores das coordenados da Curva ROC para a Pressão Arterial Sistólica (PAS) no $4^{\circ}$ dia do Teste de Fludrocortisona

\section{Curva ROC}

\begin{tabular}{|ccc}
\hline Valores absolutos da Variação da PAS & Sensibilidade & 1-Especificidade \\
\hline $\mathbf{- 2 , 1 7}$ & 0,60 & 0,50 \\
\hline $\mathbf{- 1 , 9 2}$ & 0,60 & 0,53 \\
$\mathbf{- 1 , 6 3}$ & 0,63 & 0,53 \\
$\mathbf{- 1 , 3 3}$ & 0,63 & 0,56 \\
\hline $\mathbf{- 0 , 9 3}$ & 0,63 & 0,60 \\
\hline $\mathbf{- 0 , 2 9}$ & 0,66 & 0,60 \\
\hline $\mathbf{0 , 3 3}$ & 0,66 & 0,63 \\
$\mathbf{0 , 6 7}$ & 0,70 & 0,63 \\
\hline $\mathbf{1 , 1 3}$ & 0,73 & 0,63 \\
$\mathbf{1 , 5 0}$ & 0,73 & 0,66 \\
\hline $\mathbf{2 , 0 7}$ & 0,76 & 0,66 \\
$\mathbf{3 , 1 3}$ & 0,80 & 0,66 \\
\hline $\mathbf{3 , 8 1}$ & 0,80 & 0,70 \\
$\mathbf{4 , 4 5}$ & 0,80 & 0,73 \\
\hline $\mathbf{5 , 0 3}$ & 0,83 & 0,73 \\
\hline $\mathbf{5 , 3 8}$ & 0,86 & 0,73 \\
\hline $\mathbf{5 , 6 9}$ & 0,90 & 0,73 \\
\hline $\mathbf{6 , 8 1}$ & 0,90 & 0,76 \\
\hline $\mathbf{8 , 5 9}$ & 0,90 & 0,80 \\
\hline $\mathbf{9 , 6 4}$ & 0,93 & 0,80 \\
\hline $\mathbf{1 0 , 6 7}$ & 0,93 & 0,83 \\
\hline $\mathbf{1 1 , 5 7}$ & 0,93 & 0,86 \\
\hline $\mathbf{1 1 , 8 8}$ & 0,96 & 0,86 \\
\hline & & \\
\hline
\end{tabular}


Anexo 4 - Valores das coordenados da Curva ROC para a Pressão Arterial Sistólica (PAS) no $7^{\circ}$ dia do Teste de Fludrocortisona

\section{Curva ROC}

\begin{tabular}{|ccc}
\hline Valores absolutos da Variação da PAS & Sensibilidade & 1-Especificidade \\
\hline $\mathbf{- 3 , 5 7}$ & 0,70 & 0,10 \\
$\mathbf{- 2 , 9 8}$ & 0,70 & 0,13 \\
$\mathbf{- 1 , 9 0}$ & 0,70 & 0,16 \\
$\mathbf{- 1 , 2 5}$ & 0,73 & 0,16 \\
$\mathbf{- 0 , 9 2}$ & 0,73 & 0,20 \\
$\mathbf{- 0 , 6 7}$ & 0,73 & 0,23 \\
$\mathbf{- 0 , 5 6}$ & 0,76 & 0,23 \\
$\mathbf{- 0 , 2 5}$ & 0,76 & 0,26 \\
$\mathbf{0 , 1 5}$ & 0,76 & 0,30 \\
$\mathbf{0 , 4 4}$ & 0,80 & 0,30 \\
$\mathbf{0 , 9 0}$ & 0,83 & 0,30 \\
$\mathbf{1 , 2 3}$ & 0,83 & 0,33 \\
$\mathbf{2 , 8 0}$ & 0,83 & 0,36 \\
$\mathbf{4 , 4 2}$ & 0,83 & 0,40 \\
$\mathbf{5 , 1 0}$ & 0,83 & 0,43 \\
$\mathbf{6 , 0 5}$ & 0,83 & 0,46 \\
$\mathbf{6 , 4 3}$ & 0,83 & 0,50 \\
$\mathbf{6 , 7 7}$ & 0,83 & 0,53 \\
\hline $\mathbf{7 , 1 3}$ & 0,83 & 0,56 \\
\hline $\mathbf{7 , 4 0}$ & 0,86 & 0,56 \\
$\mathbf{7 , 6 5}$ & 0,90 & 0,56 \\
$\mathbf{8 , 5 1}$ & 0,90 & 0,60 \\
$\mathbf{9 , 3 3}$ & 0,93 & 0,60 \\
$\mathbf{9 , 6 2}$ & 0,93 & 0,63 \\
$\mathbf{1 0 , 2 2}$ & 1,00 & 0,63 \\
\hline & & \\
\hline
\end{tabular}


Anexo 5 - Valores das coordenados da Curva ROC para a Pressão Arterial Média (PAM) no $7^{\circ}$ dia do Teste de Fludrocortisona

Curva ROC

\begin{tabular}{|ccc}
\hline Valores absolutos da Variação da PAM & Sensibilidade & 1-Especificidade \\
\hline$-\mathbf{2 , 0 9}$ & 0,60 & 0,26 \\
$\mathbf{- 1 , 9 3}$ & 0,60 & 0,30 \\
$\mathbf{- 1 , 6 2}$ & 0,63 & 0,30 \\
$\mathbf{- 1 , 1 0}$ & 0,63 & 0,33 \\
$\mathbf{- 0 , 7 1}$ & 0,63 & 0,36 \\
$\mathbf{- 0 , 5 6}$ & 0,66 & 0,36 \\
\hline $\mathbf{- 0 , 0 7}$ & 0,66 & 0,40 \\
$\mathbf{0 , 4 4}$ & 0,66 & 0,43 \\
$\mathbf{0 , 6 7}$ & 0,70 & 0,43 \\
\hline $\mathbf{1 , 1 5}$ & 0,73 & 0,43 \\
$\mathbf{1 , 5 7}$ & 0,76 & 0,43 \\
$\mathbf{2 , 1 2}$ & 0,76 & 0,46 \\
$\mathbf{2 , 9 5}$ & 0,80 & 0,46 \\
\hline $\mathbf{3 , 8 5}$ & 0,80 & 0,50 \\
$\mathbf{4 , 4 6}$ & 0,80 & 0,53 \\
\hline $\mathbf{4 , 7 1}$ & 0,80 & 0,56 \\
\hline $\mathbf{5 , 0 3}$ & 0,83 & 0,56 \\
$\mathbf{5 , 1 1}$ & 0,86 & 0,56 \\
\hline $\mathbf{5 , 3 1}$ & 0,86 & 0,60 \\
\hline $\mathbf{5 , 5 7}$ & 0,86 & 0,63 \\
$\mathbf{5 , 8 2}$ & 0,90 & 0,63 \\
$\mathbf{6 , 2 3}$ & 0,90 & 0,66 \\
$\mathbf{6 , 7 2}$ & 0,90 & 0,70 \\
\hline $\mathbf{7 , 0 8}$ & 0,90 & 0,73 \\
$\mathbf{8 , 1 6}$ & 0,90 & 0,76 \\
\hline & & \\
\hline
\end{tabular}


Anexo 6 - Carta de aprovação no comitê de ética

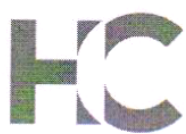

\section{APROVAÇÃO}

A Comissão de Ética para Análise de Projetos de Pesquisa CAPPesa da Diretoria Clínica do Hospital das Clínicas e da Faculdade de Medicina da Universidade de São Paulo, em sessão de 25/08/2010, APROVOU o Protocolo de Pesquisa n 0343/10, intitulado: 'TESTE RÁPIDO DA FLUDROCORTISONA NA IDENTIFICAÇÃO DA SENSIBILIDADE A SAL." apresentado pelo Departamento de CLÍNICA MÉDICA, inclusive o Termo de Consentimento Livre e Esclarecido.

Cabe ao pesquisador elaborar e apresentar à CAPPesq, os relatórios parciais e final sobre a pesquisa (Resolução do Conselho Nacional de Saúde n 196, de 10/10/1996, inciso IX.2, letra "c").

Pesquisador (a) Responsável: Decio Mion Junior

Pesquisador (a) Executante: Andrea Pio de Abreu

CAPPesq, 26 de Agosto de 2010

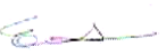

Prof. Dr. Eduardo Massad Presidente da Comissão de Ética para Análise de Projetos de Pesquisa

\footnotetext{
Comissão de Ética para Análise de Projetos de Pesquisa do HCFMUSP e da FMUSP Diretoria Clinica do Hospital das Clínicas da Faculdade de Medicina da Universidade de São Paulo Rua Ovidio Pires de Campos, 225, $5^{\circ}$ andar - CEP 05403010 - São Paulo - SP Fone: 01130696442 Fax: 01130696492 e-mail: cappesq@hcnet.usp.br/ secretariacappesq2@hcnet.usp.br
} 


\section{REFERÊNCIAS BIBLIOGRÁFICAS}

1. Kaplan NM. Kaplan's Clinical Hypertension (9th ed.). Philadelphia, PA: Lippincott, Williams e Wilkins. 2006; 50-112.

2. Kearney PM, Whelton M, Reynolds K, et al. Global burden of hypertension: analysis of worldwide data. Lancet. 2005; 365: 217- 223.

3. World Health Organization. A global brief on hypertension: silent killer, global public health crisis. World Health Day 2013. Report. 2013; 1-39 [online].

Disponível: http://www.who.int/cardiovascular_diseases/publications/global_brief_hypert ension/en/

4. Cipullo JP, Martin JF, Ciorlia LA, Godoy MR, Cação JC, Loureiro AA, et al. Hypertension prevalence and risk factors in a Brazilian urban population. Arq Bras Cardiol. 2010; 94(4):519-26.

5. Elliott P, Stamler J, Nichols R, Dyer AR, Stamler R, Kesteloot $H$, at al for the INTERSALT Cooperative Research Group. INTERSALT revisited: further analyses of 24 hour sodium excretion and blood pressure within and across populations. BMJ 1996; 312: 1249-53.

6. Mozaffarian $D$, Fahimi S, Singh GM, et al. Global sodium consumption and death from cardiovascular causes. $N$ Engl $J$ Med. 2014; 371(7):624-34.

7. Cutler JA, Follmann D, Allender PS. Randomized trials of sodium reduction: an overview. Am J Clin Nutr 1997; 65 (suppl 2): S 643-51.

8. He FJ, MacGregor GA. How far should salt intake be reduced? Hypertension 2003; 42: 1093-9.

9. He FJ, MacGregor GA. Effect of longer-term modest salt reduction on blood pressure. Cochrane Database Syst Rev 2004; (3): CD004937.

10.INTERSALT Cooperative Research Group: INTERSALT Study: an international study of electrolyte excretion and blood pressure: Results for 24-hour urinary sodium and potassium excretion. BMJ 1988; 297: 319-328.

11. Midgley JP, Matthew AG, Greenwood CMT et al: Effect of reduced dietary sodium on blood pressure: a meta-analysis of randomized controlled trials. JAMA 1996; 275: 1590 - 1597.

12. Hooper L, Bartlett C, Smith GD, et al: Systematic review of long term effects of advice to reduce dietary salt in adults. BMJ 2002; 325: 628 - 636.

13. Taylor RS, Ashton KE, Moxham T, et al. Reduced dietary salt for the prevention of cardiovascular disease: a meta-analysis of randomized controlled trials (Cochrane review). Am J Hypertens. 2011 Aug; 24(8): 84353.

14. Elliott P, Stamler J, Nichols $R$, et al. for the INTERSALT Cooperative Research Group: INTERSALT revisited: Further analyses of 24-hour sodium excretion and blood pressure within and across populations. BMJ 1996; 312: 1249 - 1253.

15. Hanneman RL: INTERSALT: Hypertension rise with age revisited. BMJ 1996; 312:1283 - 1284.

16.Davey Smith G, Phillips AN: Inflation in epidemiology: "The proof and measurement of association between two things" revisited. BMJ 1996; 312: 1659- 1664. 
17. He J, Klag MJ, Whelton PK, et al: Migration, blood pressure pattern, and hypertension: the Yi Migrant Study. Am J Epidemiol 1991; 134: 1085-1101.

18. Poulter NR, Khaw KT, Hopwood BE, et al: The Kenyan Luo migration study: observations on the initiation of a rise in blood pressure. BMJ 1990; 300: 967-972.

19. Poulter NR, Khaw KT, Mugambi M, et al. Migration-induced changes in blood pressure: a controlled longitudinal study. Clin Exp Pharmacol Physiol. 1985; 12: 211 - 216.

20. He J, Klag MJ, Whelton PK, et al. Migration, blood pressure pattern, and hypertension: the Yi Migrant Study. Am J Epidemiol.1991; 134: 1085 - 1101.

21. Hollenberg NK, Martinez G, McCullough M, et al: Aging, acculturation, salt intake, and hypertension in the Kuna of Panama. Hypertension 1997; 29: 171-176.

22. Forte JG, Miguel JM, et al: Salt and blood pressure: a community trial. $J$ Hum Hypertens 1989; 3: 179 - 184.

23. He FJ, Li J, MacGregor GA. Effect of longer-term modest salt reduction on blood pressure. Cochrane Database Syst Rev. 2013 Apr 30; 4:CD004937.

24. Strazzullo P, D’Elia L, Kandala NB, Cappuccio FP. Salt intake, stroke and cardiovascular disease: meta-analysis of prospective studies. BMJ 2009; 339: b4567.

25. Cook NR, Cutler JA, Obarzanek E, et al. Long term effects of dietary sodium reduction on cardiovascular disease outcomes: observational follow-up of trials of hypertension prevention (TOHP). BMJ 2007; 334 (7599); 885.

26. Feng J. He, MacGregor G.A: Reducing population salt intake worldwide: From evidence to Implementation. Progress in Cardiovasc Diseases 2010; 52: 363-382.

27. Alderman $\mathrm{MH}$. Reducing dietary sodium: the case for caution. JAMA 2010; 303 (5): 448-9.

28. Alderman $\mathrm{MH}$, Cohen HW. Dietary sodium intake and cardiovascular mortality: controversy resolved? Curr Hypertens Rep 2012; 14: 193-201.

29. Hamet, P, Mongeau E., Lambert J. et al. Interaction among calcium, sodium, and alcohol intake as a determinants of blood pressure. Hypertension 1991; 17: $150-154$.

30. Miller JZ, Weinberger MH, Daugherty SA, et al: Heterogeneity of blood pressure response to dietary sodium restriction in normotensive adults. $J$ Chron Dis 1987, 40: 245-250.

31. M.H. Weinberger: Sodium sensitivity of blood pressure, Curr. Opin. Nephrol. Hypertens 1993; 2: 935-939.

32. Gonzalez-Albarran, et al: Salt Sensitivity: Concept and Pathogenesis. Diabetes Research and Clinical Practice 1998; 39 (Suppl): S15- S26.

33. Campese, V.M: Effects of calcium antagonists on deranged modulation of renal function curve in salt-sensitive patients with essential hypertension, Am. J. Cardiol 1988; 62: 85G-91G.

34. Kimura, G., Ashida T., Abe $\mathrm{H}$, et al. Sodium sensitive and sodium retaining hypertension, Am. J. Hypertens 1990; 3: 398-406.

35. Hollenberg, N.K. et al: Abnormal renal sodium handling in essential hypertension, Am. J. Med 1986; 81: 412-418. 
36. Campese, V.M., Parise, M., Karubian, F., Bigazzi, R. Abnormal renal hemodynamics in black salt-sensitive patients with hypertension, Hypertension 1991; 18: 805-812.

37. Weinberger MH, Miller JZ, Luft FC, Grim CE, Fineberg NS: Definitions and characteristics of sodium sensitivity and blood pressure resistance. Hypertension 1986; 8(6 Pt2): II127-34.

38. Luft FC, Weinberger $\mathrm{MH}$ et al: Salt sensitivity and resistance of blood pressure. Age and race as factors in physiological responses. Hypertension. 1991; 17: I102-I108

39. Weinberger $\mathrm{MH}$ : Salt sensitivity of blood pressure in humans. Hypertension. 1996; 27 (3 Pt 2): 481-490.

40.Sanders PW: Dietary salt intake, salt sensitivity, and cardiovascular health. Hypertension. 2009; 53 (3): 442-5.

41. Morris RC, Jr, et al: Normotensive salt sensitivity: effects of race and dietary potassium. Hypertension. 1999; 33 (1): 18-23.

42. De Boer, MP, ljzerman RG, de Jongh RT, Eringa EC et al: Birth weight relates to salt sensitivity of blood pressure in healthy adults. Hypertension 2008; 51 (4): 928-32.

43.Zhao et al: Common Variants in Epithelial Sodium Channel Genes Contribute to Salt Sensitivity of Blood Pressure: The GenSalt Study. Circulation Cardiovasc Genetics 2011; 4: 375-380.

44. Sullivan JM. Salt sensitivity: definition, conception, methodology, and longterm issues. Hypertension 1991; 17 (suppl I): I-61-I-68.

45. Sharma AM, Ruland $\mathrm{K}$, Spies $\mathrm{KP}$, et al: Salt sensitivity in young normotensive subjects is associated with a hyperinsulinemic response to oral glucose. J Hypertens 1991; 9: 329 - 335.

46. Galletti F, Strazzullo P, Ferrara I, Annuzzi G, Rivellese AA, Gatto S, Mancini $\mathrm{M}$. $\mathrm{NaCl}$ sensitivity of essential hypertensive patients is related to insulin resistance. J Hypertens. 1997; 15: 1485 - 1491.

47. Bigazzi R, Bianchi S, Baldari D, Sgberri G, Baldari G, Campese VM. Microalbuminuria in salt-sensitive patients: a marker for renal and cardiovascular risk factors. Hypertension 1994; 3: 195-199.

48. Higashi Y, Oshima T, Ozono R, et al. Nocturnal decline in blood pressure is attenuated by $\mathrm{NaCl}$ loading in salt-sensitive patients with essential hypertension: noninvasive 24-hour ambulatory blood pressure monitoring. Hypertension 1997; 30: 163 - 167.

49. Brotman DJ, et al: Impaired diurnal blood pressure variation and all-cause mortality. Am J Hypertens 2008; 21 (1): 92 - 97.

50. Weinberger, HM. Salt sensitivity is associated with an increased mortality in both normal and hypertensive humans. Journal Clinical Hypertension 2002; 4: 274-6.

51. Heimann JC, Drumond S, Alves AT et al: Left ventricular hypertrophy is more marked in salt-sensitive than in salt-resistant hypertensive patients. Cardiovasc Pharmacol 1991; 17 Suppl 2: S122-4.

52. Morimoto A; Uzu T; Fujii T, et al: Sodium sensitivity and cardiovascular events in patients with essential hypertension. Lancet, 1997; 350: 1734 1737. 
53.F.C. Luft, C.E. Grim, J.T. Higgins Jr, M.H. Weinberger, Differences in response to sodium administration in normotensive white and blacks subjects. J. Lab. Clin. Med. 1997; 90: 555-562.

54. T. Kawasaki, CS et al. The effect of high-sodium and low-sodium intakes on blood effect of high-sodium and low-sodium intakes on blood pressure and other related variables in human subjects with idiopathic hypertension. Am. J. Med. 1978 64: 194-198.

55. Sharma AM, Schattenfroh S, Kribben A, et al. Reliability of salt-sensitivity testing in normotensive subjects. Klin Wochenschr 1989; 67-71.

56. World Health Organization. Reducing salt intake in populations: report of a WHO fórum and technical meeting, 2007 [ Acesso em 2 de março de 2013]; Disponível:

http//www.who.int/dietphysicalactivity/Salt_Report_VC_april07.pdf.

57. Mion Jr D, Rea RF, Anderson EA et al. Effects of fludrocortisone on sympathetic nerve activity in humans. Hypertension 1994; 23: 123-130.

58. Mano GMP, Souza, VF, Pierin, AMG et al. Avaliação do Aparelho Automático Oscilométrico de Medida da Pressão Arterial DIXTAL DX-2710 pelos Protocolos de Validação da British Hypertension Society (BHS) e Association for the Advancement of Medical Instrumentation (AAMI). Arq Bras Cardiol 2002; volume 79 (ํㅜ 6):601-5.

59. Sociedade Brasileira de Cardiologia. Sociedade Brasileira de Hipertensão. Sociedade Brasileira de Nefrologia. V Diretriz Brasileira de Monitorização Ambulatorial da Pressão Arterial (MAPA) e III Diretrizes Brasileiras de Monitorização Residencial da Pressão Arterial (MRPA). Arq Bras Cardiol 2011; 97 (supl.3):1-24

60. Wingenfeld $\mathrm{K}$ et al. Enhanced emotional empathy after mineralocorticoid receptor stimulation in women with borderline personality disorder and healthy women._Neuropsychopharmacology. 2014 Jul; 39(8): 1799 - 804.

61. Christian Otte et al. Mineralocorticoid Receptor Stimulation Improves Cognitive Function and Decreases Cortisol Secretion in Depressed Patients and Healthy Individuals. Neuropsychopharmacology 2015, 40: 386-393

62. Ishikawa SE et al. Hyponatremia responsive to fludrocortisone acetate in elderly patients after head injury. Ann Intern Med 1987; 106(2):187-91.

63. Jones B, Kenward MG. Design and analysis of cross-over trials (1th ed). New York, Chapman and Hall, 1989. 1-10.

64. De la Sierra A, Giner V, Bragulat E, Coca A. Lack of correlation between two methods for the assessment of salt sensitivity in essential hypertension. Journal of Human Hypertension 2002; 16: 255 - 260.

65. Felder RA, White MJ, Williams SM et al. Diagnostic tools for hypertension and salt sensitivity testing. Curr Opin Nephrol Hypertens. 2013; 22 (1):65-76.

66. Nichols J, Elijovich F, Laffer CL. Lack of validation of a same-day outpatient protocol for determination of salt sensitivity of blood pressure. Hypertension; 2012; 59 (2): 390 - 4.

67. Willenberg HS1, Vonend $\mathrm{O}$, Schott $\mathrm{M}$, et al. Comparison of the saline infusion test and the fludrocortisone suppression test for the diagnosis of primary aldosteronism. Horm Metab Res. 2012; 44 (7): 527 - 32. 